\title{
Scars in the abyss: reconstructing sequence, location and temporal change of the 78 plough tracks of the 1989 DISCOL deep-sea disturbance experiment in the Peru Basin
}

\author{
Florian Gausepohl ${ }^{1,2}$, Anne Hennke ${ }^{1}$, Timm Schoening ${ }^{1}$, Kevin Köser ${ }^{1}$, and Jens Greinert ${ }^{1,2}$ \\ ${ }^{1}$ GEOMAR Helmholtz Centre for Ocean Research Kiel, Kiel, Germany \\ ${ }^{2}$ Department of Geosciences, Kiel University, Kiel, Germany
}

Correspondence: Anne Hennke (ahennke@geomar.de)

Received: 6 September 2019 - Discussion started: 16 October 2019

Revised: 23 January 2020 - Accepted: 31 January 2020 - Published: 23 March 2020

\begin{abstract}
High-resolution optical and hydro-acoustic sea floor data acquired in 2015 enabled the reconstruction and exact localization of disturbance tracks of a past deep-sea recolonization experiment (DISCOL) that was conducted in 1989 in the Peru Basin during a German environmental impact study associated with manganese-nodule mining. Based on this information, the disturbance level of the experiment regarding the direct plough impact and distribution and redeposition of sediment from the evolving sediment plume was assessed qualitatively. The compilation of all available optical and acoustic data sets available from the DISCOL Experimental Area (DEA) and the derived accurate positions of the different plough marks facilitate the analysis of the sedimentary evolution over the last 26 years for a sub-set of the 78 disturbance tracks. The results highlight the remarkable difference between natural sedimentation in the deep sea and sedimentation of a resettled sediment plume; most of the blanketing of the plough tracks happened through the resettling of plume sediment from plough tracks created later. Generally sediment plumes are seen as one of the important impacts associated with potential Mn-nodule mining.

For enabling a better evaluation and interpretation of particularly geochemical and microbiological data, a relative age sequence of single plough marks and groups of them was derived and is presented here. This is important as the thickness of resettled sediment differs distinctly between plough marks created earlier and later.

Problems in data processing became eminent for data from the late 1980s, at a time when GPS was just invented and underwater navigation was in an infant stage. However, even
\end{abstract}

today the uncertainties of underwater navigation need to be considered if a variety of acoustical and optical sensors with different resolution should be merged to correlate accurately with the absolute geographic position. In this study, the ship-based bathymetric map was used as the absolute geographic reference layer and a workflow was applied for georeferencing all the other data sets of the DISCOL Experimental Area until the end of 2015. New high-resolution field data were mainly acquired with sensors attached to GEOMAR's AUV Abyss and the $0.5^{\circ} \times 1^{\circ}$ EM122 multibeam system of RV Sonne during cruise SO242-1. Legacy data from the 1980s and 1990s first needed to be found and compiled before they could be digitized and properly geo-referenced for our joined analyses.

\section{Introduction}

\subsection{Ecological risks associated with Mn-nodule mining from the deep-sea floor}

For several years, mining of manganese (Mn) nodules from the deep-sea floor is again considered a worthwhile option to meet future resource demands. Several nations have secured exploration contracts in areas beyond any national jurisdiction as they seek economic benefits and/or aim for technological leadership in terms of deep-sea mining. Current plans for a future mining scenario involve collectors that will move on the sea floor gathering Mn nodules from the top 10 to $30 \mathrm{~cm}$ of the sediment, most likely using a hy- 
draulic collection mechanism (Kuhn et al., 2011; Oebius et al., 2001). This principle implies considerable consequences for the benthic environment in the mined area. Besides the removal of the Mn nodules as an important hard-substrate habitat on the abyssal plains (Purser et al., 2016; Vanreusel et al., 2016; Thiel et al., 1993), the mining activities will completely rework the top sediment layers and resuspend large amounts of sediment into the water column. Depending on the plume properties such as particle size, flocculation behaviour, sediment mass per litre and the prevailing current conditions, these sediment particles might be transported outside the mined area. The deposition of this material will cause a secondary impact on the environment by clogging filter feeders and burying the sessile fauna, which are both adapted to the low sedimentation rates in the deep sea (Thiel and Schriever, 1989). Resedimentation of this material can also lead to differences in local geochemical gradients and consequently might influence the recolonization processes of the primary and secondary disturbed areas. To evaluate these effects on the environment, several benthic impact experiments (BIEs) and one Recolonization Experiment, the German Research Project "Disturbance and Recolonization Experiment - DISCOL" (http://www.discol.de, last access: 5 March 2020), have been conducted in the past within different large Mn-nodule areas, including the Peru Basin (Thiel and Schriever, 1989), the central equatorial Pacific (e.g. Burns, 1980; Fukushima, 1995) or the Indian Ocean Basin (Desa, 1997). Information about the sediment plume dispersal during the different large-scale disturbances is compiled in Sect. 1.2. A review of the biological responses to such BIEs was recently presented by Jones et al. (2017), and studies by Simon-Lledó et al. (2019) in the DISCOL Experimental Area (DEA) show that colonization pattern differences still exist between the disturbed and undisturbed areas even after 26 years.

\subsection{Summary of plume dispersal results of past benthic impact experiments (BIEs)}

In the late 1970 s, the first so-called "mining test" operations were conducted in the central North Pacific as part of the DOMES project (Ozturgut et al., 1978, 1980) that used a suction dredge towed on skis to create a disturbance for illustrating potential mining impacts. Here, the experimental area was surveyed before, during and after the experiment, with each disturbance lasting for several hours (see Table A1 in Appendix A for details on location, duration, monitoring techniques and impacted area). For the first three tests in spring 1978, operated by Ocean Mining Inc. (OMI), detailed data about the induced sediment plume were derived from different sampling methods including sediment coring and sediment traps (see Burns, 1980, and details in Table A1), and results indicate a plume dispersal of up to $16 \mathrm{~km}$ downstream of the created disturbance (Table A1). Model results based on the OMI experiment indicate a sed- iment blanketing thickness of $\leq 1 \mathrm{~mm}$ beyond a $400 \mathrm{~m}$ distance to single disturbance tracks. An extrapolation of these results for a potential mining scenario was performed and predicted a distribution of resuspended sediment particles of up to $160 \mathrm{~km}$ distance (Lavelle et al., 1981). Another mining test phase in November 1978 focused on the distribution of a surface discharge plume (Ozturgut et al., 1980). During an $18 \mathrm{~h}$ operation by Deepsea Ventures Inc. and Ocean Mining Associates (OMA), a second sea floor mining test was conducted in November 1978 by the Ocean Minerals Company (OMCO) using a remote-controlled self-propelled miner (RCM) (Chung, 2009). This vehicle removed approximately $4 \mathrm{~cm}$ of the upper sediment layer (Khripounoff et al., 2006), creating a track of $1.5 \mathrm{~m}$ width (Miljutin et al., 2011). The aim of this experiment was mainly to test the mining technology and not to monitor the benthic impact of the plume. Hence, detailed information regarding the sediment plume dispersal right after the impact is missing. In 2004, the disturbed area was revisited and investigated for its ecological recovery (Mahatma, 2009; Miljutin et al., 2011), indicating only a near-track influence of redeposited sediment.

Chronologically the next and largest ever created disturbance was conducted in the DISCOL Experimental Area in the Peru Basin. For creating the disturbance, a plough harrow (8 $\mathrm{m}$ width) was towed 78 times crisscrossing through a circular area of $2 \mathrm{nmi}$ in diameter (Thiel and Schriever, 1989). Due to technical problems the deployed nephelometers at that time did not detect the sediment plume and the amount of suspended material remains largely uncertain. Nevertheless, the presence of a plume in the water column about $6 \mathrm{~h}$ after the last plough deployment was confirmed by visual observations (Thiel and Schriever, 1989). Numerical modelling predicted a dispersal of the suspended sediment for several kilometres with coverages of resettled material of $>100 \mathrm{~g} \mathrm{~m}^{-2}$ up to a distance of $2 \mathrm{~km}$ (Jankowski et al., 1996; Table A1). The effects of the disturbance were investigated just after the experiment (RV Sonne cruise SO61; Thiel and Schriever, 1989) as well as 0.5 (cruise SO64; Schriever, 1990), 3 (cruise SO77; Schriever and Thiel, 1992), 7 (cruise SO106; Schriever et al., 1996) and finally 26 years later (cruise SO 242; Boetius, 2015; Greinert, 2015) to document the environmental impact, the recolonization and the sediment geochemical equilibration of the disturbed sites in comparison to a number of undisturbed reference sites in the vicinity.

Again north of the Equator, the first large-scale benthic disturbance experiment in the eastern Clarion-Clipperton Fracture Zone (CCFZ) conducted by the United States was the Benthic Impact Experiment II (BIE-II) in 1993, using the "Deep Sea Sediment Resuspension System" (DSSRS) (Brockett and Richards, 1994; Tsurusaki, 1997) as the disturbance tool (Trueblood and Ozturgut, 1997). The initiated sediment plume was monitored with camera systems, sediment traps and transmissiometers, which were moored at different distances from the tow zone in order to estimate the 
distribution areas of resettled sediment and the plume dispersal in the water column. The studies revealed an area of strong sediment blanketing within the first $50 \mathrm{~m}$ downstream of the disturbance and a decreasing blanketing thickness with increasing distance. Moorings located $400 \mathrm{~m}$ away still detected suspended material passing by and also deployed sediment trap samples indicating a maximum "blanketing" thickness of $1 \mathrm{~mm}$. In contrast to these data, camera observations suggested a sediment blanketing thickness of $1-2 \mathrm{~cm}$ close to the disturbance zone (Jones, 2000) already indicating that the sediment traps might have missed the additional sediment transport of initiated gravity flows just above the sea floor.

A total of 1 year after the American experiment, the Metal Mining Agency of Japan (MMAJ) carried out another disturbance study within the CCFZ, the "Japan Deep sea Impact Experiment" (JET) in 1994 (Fukushima, 1995). The disturbance was again created with the DSSRS (Tsurusaki, 1997). The distribution of the initiated sediment plume was analysed using two different approaches. One approach measured the thickness of the blanketing sediment layer using sediment traps and spatially interpolated the results using kriging. A dispersal of $2.5 \mathrm{~km}$ in length and approximately $1 \mathrm{~km}$ in width was calculated and a maximum blanketing thickness of $2.6 \mathrm{~mm}$ was determined (Barnett and Suzuki, 1997). The second approach used visual data from deep-towed camera surveys to estimate the extent of the sediment blanketing that covered the Mn nodules. Respective results show that the "heavy" resedimentation area, defined by a thickness $>0.26 \mathrm{~mm}$, did not extend for more than $100 \mathrm{~m}$ away from the disturbance track. Thinner blanketing $<0.26 \mathrm{~mm}$ was observed over an area of $\sim 3 \mathrm{~km}$ length and $\sim 2.5 \mathrm{~km}$ width around the disturbance (Yamazaki and Kajitani, 1999), covering a much wider area compared to the kriging approach.

In 1995, the Interoceanmetal Joint Organization (IOM) conducted a benthic disturbance experiment (IOM-BIE) over an area of $2000 \mathrm{~m} \times 1500 \mathrm{~m}$ also in the eastern CCFZ, once more using the DSSRS (Kotlinski and Stoyanova, 1999; Radziejewska, 2002). Studies focused on the physical and chemical properties of the resuspended and resettled sediments rather than on the spatial distribution of the material; this leads to only limited information on the amount of resuspended material. Radziejewska (2002) estimated the volume of resuspended material to be approximately $1800 \mathrm{~m}^{3}$ over the entire duration of the experiment, but the actual volume is not known.

In 1997, the "Indian Deep sea Environment Experiment" (INDEX) was carried out in the Central Indian Ocean Basin. For the fourth time, the DSSRS was used to create the disturbance during 9d of operation (Desa, 1997; Sharma and Nath, 1997). Results from sediment traps distributed up to $800 \mathrm{~m}$ away from the track show an increase in average particle fluxes from 48 to $150 \mathrm{mg} \mathrm{m}^{-2} \mathrm{~d}^{-1}$ during the disturbance phase. The flux decreased to $95 \mathrm{mg} \mathrm{m}^{-2} \mathrm{~d}^{-1}$ within the first $6 \mathrm{~d}$ after the disturbance stopped (Sharma, 2001). Based on visual observations, most of the sediment particles resettled already within $150 \mathrm{~m}$ from the edge of the disturbance area (Sharma et al., 2001), with the major part of material settling within an approximately $100 \mathrm{~m}$ distance (Sharma, 2000).

The last large-scale BIE was conducted in 1997 by MMAJ within the area of the Marcus-Wake Seamounts in the North Pacific Ocean (Yamada and Yamazaki, 1998). The induced sediment plume was visually monitored (Yamazaki et al., 1999) and data revealed a sediment blanketing thickness on top of Mn nodules of up to $0.2 \mathrm{~mm}$ (Yamazaki et al., 2001). Due to the different geological setting (seamount in $2200 \mathrm{~m}$ water depth) and different sediment properties (calcareous sediments, coarser sediment particles, stronger currents), these results are not directly comparable to the results from most of the other BIEs mentioned above.

Reviewing the different large-scale BIEs and pilot mining tests conducted between the late 1970s and late 1990s, it becomes obvious that the different experimental setups and the missing uniform definition of "a" plume (grain size distribution, flocculation behaviour, total mass per litre, settling velocity, etc.) make it impossible to use the presented information for a meaningful prediction of the behaviour of a sediment plume created during a real deep-sea mining operation (Peukert et al., 2018). Thus reconstructing the initial disturbance of 1989 in the DISCOL area, which is considered to be the most extensively sampled and monitored BIE site, might help to gain new and more conclusive insights in terms of the distribution of resuspended and redeposited sediment during and shortly after conducting the disturbance and consequently be used as a basis for sample interpretation from this area.

This study presents new data from the DEA, which were acquired in 2015 during RV Sonne cruise SO242-1 with state-of-the-art AUV multibeam and side-scan sonar systems, cameras and underwater navigation technology (Greinert, 2015).

\subsection{DISCOL revisited in 2015 and objectives of this study}

Since 1989, major technological advancements improved deep-sea investigations with regard to data acquisition technologies and positioning accuracy. In 1989 GPS for example was not as sophisticated and high-resolution acoustic sea floor mapping with multibeam echo sounder systems (MBES) was not as developed as it is today (e.g. 59 beams compared to 432 beams; single swath compared to dual swath; Lurton, 2017). AUV-based technologies did not exist.

To acquire the most accurate data of the old plough tracks, the entire DISCOL area was re-mapped using ship- and AUV-based hydro-acoustic MBESs with different resolution (Boetius, 2015; Greinert, 2015). This provided new information for reconstructing the extent and impact of the initial disturbance experiment, the different geological settings within and next to the DEA, and related varying habitats. The results presented in this study mainly focus on the data 
collected by GEOMAR's AUV Abyss (Linke and Lakschewitz, 2016, https://doi.org/10.17815/jlsrf-2-149). The AUV was deployed in three different modes running MBES, sidescan sonar (SSS) or a photo camera system enabling autonomous mapping with a resolution of $2 \mathrm{~m}$ for bathymetric data, $0.5 \mathrm{~m}$ for SSS data and a few millimetre per pixel for photo surveys. All systems show clear evidence of the disturbance tracks created by the plough harrow 26 years before.

This study presents the best geo-referenced data set of the study area through a combined processing of the available ship- and AUV-obtained acoustic and optical data. In addition to this mapping exercise, the succession of the disturbance tracks as well as their correct location are reconstructed, as this could not accurately be documented in 1989 . Although the 78 plough tracks were created over a period of only 4 weeks (Thiel and Schriever, 1989), a more detailed understanding of their sequence is relevant regarding faunal differences from within or close to plough tracks in strongly or more weakly disturbed parts of the DEA. Furthermore for the understanding of varying down-core geochemical gradients, the spatial thickness change of the resettled sediment, the "blanketing", needs to be understood. This thickness distinctly differs between the plough tracks depending on if they were created in an earlier or later stage of the disturbance, which highlights the difference between high plume sedimentation rates and natural deep-sea low sedimentation rates. Next to this an unbiased and correct comparison between areas that have not been impacted by any resettled sediment with areas that have been impacted to various amounts should be performed. Interpreting biological or geochemical results correctly requires a very precise knowledge of the exact and absolute sample or footage location on the sea floor and their spatial relation to the tracks which are only a few metres wide and apart from each other. Thus a correct geo-referencing of all different data layers was a significant task of this study, and, although highly developed positioning systems were used in 2015 , uncertainties and deviations of tens to a few hundreds of metres occurred. This task became even more important for geo-referencing legacy data from 1989 for conclusively defining changes between 1989 and 2015 and spatial sediment resettling differences established already during the plough experiment.

\section{Data and methods}

\subsection{Digitizing and archiving of DISCOL legacy data}

Until 2015, the location and path of the disturbance tracks as well as the position of video and photo material of the past OFOS (Ocean Floor Observation System) surveys only existed as a vast collection of analogue (i.e. cruise reports, printed large navigational charts (Fig. 1), video cassettes and slide films) and some digital records (i.e. OFOS annotation files, sample analysis as text or EXCEL files; e.g. Bluhm,
1994; Bluhm and Thiel, 1996; Thiel and Schriever, 1989; Schriever, 1990; Schriever and Thiel, 1992; Schriever et al., 1996). In preparation for the 2015 cruise, these records were digitized and compiled in a database, also including all other available sampling stations (i.e. box corer (BC), multi-corer (MUC), moorings, baited traps; see Drazen et al., 2019) that were a part of the first four expeditions to the DEA. This database was used for station planning prior to the SO242 cruises and allows comparison of past and present disturbance levels and sea floor and ecosystem conditions at their best possible correct location.

\subsection{Hydro-acoustic and optical data acquired during cruise SO242_1}

\subsubsection{Data acquisition}

Acoustic and optical data were collected in 2015 during cruise SO242-1 with the German RV Sonne (Greinert, 2015). Large-scale bathymetric data were acquired by the hullmounted Kongsberg EM 122 MBES $\left(12 \mathrm{kHz}, 1^{\circ}\right.$ by $0.5^{\circ}$ beam angle, 432 beams, equidistance, processed with QPS Fledermaus) already on board the vessel. The system was run with a swath angle of $130^{\circ}$ at a survey speed of about 8 knots (kn). The deployed AUV (for MBES, SSS and photo surveys) is a REMUS 6000 (Linke and Lakschewitz, 2016) equipped with a RESON SeaBat 7125 MBES $\left(200 \mathrm{kHz}, 1^{\circ}\right.$ by $2^{\circ}$ beam angle) and an Edgetech $2200 \mathrm{MP}$ side-scan sonar system $(120 \mathrm{kHz})$. The MBES surveys were conducted at an altitude of $80 \mathrm{~m}$ (Abyss192 - SO242/1_047-1; Abyss 193 SO242/1_060-1; Abyss194 - SO242/1_069-1; Abyss 195 SO242/1_075-1). During the SSS surveys the altitude of the AUV was set to $40 \mathrm{~m}$ (Abyss188/SO242-1_18-1) and $20 \mathrm{~m}$ (Abyss189 - SO242/1_25-1; Abyss190 - SO242/1_33-1). The AUV camera system "DeepSurveyCam" (Kwasnitschka et al., 2016) was used during 10 photo surveys (Greinert, 2015; Simon-Lledó et al., 2019) between 4 and $9 \mathrm{~m}$ altitude and at a mean speed of $3 \mathrm{kn}$. More than 50000 usable images were recorded (Greinert, 2015) and analysed in terms of nodule coverage and size by automated image analysis (Schoening et al., 2017). Two photomosaics have been created from the AUV camera surveys Abyss196_SO242/1_83_1 (photos acquired at $7 \mathrm{~m}$ altitude) and Abyss199_SO242/1_102_1 (photos acquired at $4.5 \mathrm{~m}$ altitude).

Additional visual investigations during all cruises to the DEA were conducted using the towed camera system OFOS either equipped with both a still and video camera (Bluhm and Thiel, 1996, Thiel and Schriever, 1989; Schriever, 1990; Schriever and Thiel, 1992; Schriever et al., 1996) or just a video camera, which was mounted on the frame of a sampling device (Boetius, 2015; Greinert, 2015). The DEA was crossed by a total of 55 successful OFOS surveys, during SO61 (16 surveys - navigation data for OFOS002 and OFOS012 are missing; Thiel and Schriever, 1989), SO64 (seven surveys; Schriever, 1990), SO77 (seven surveys; 

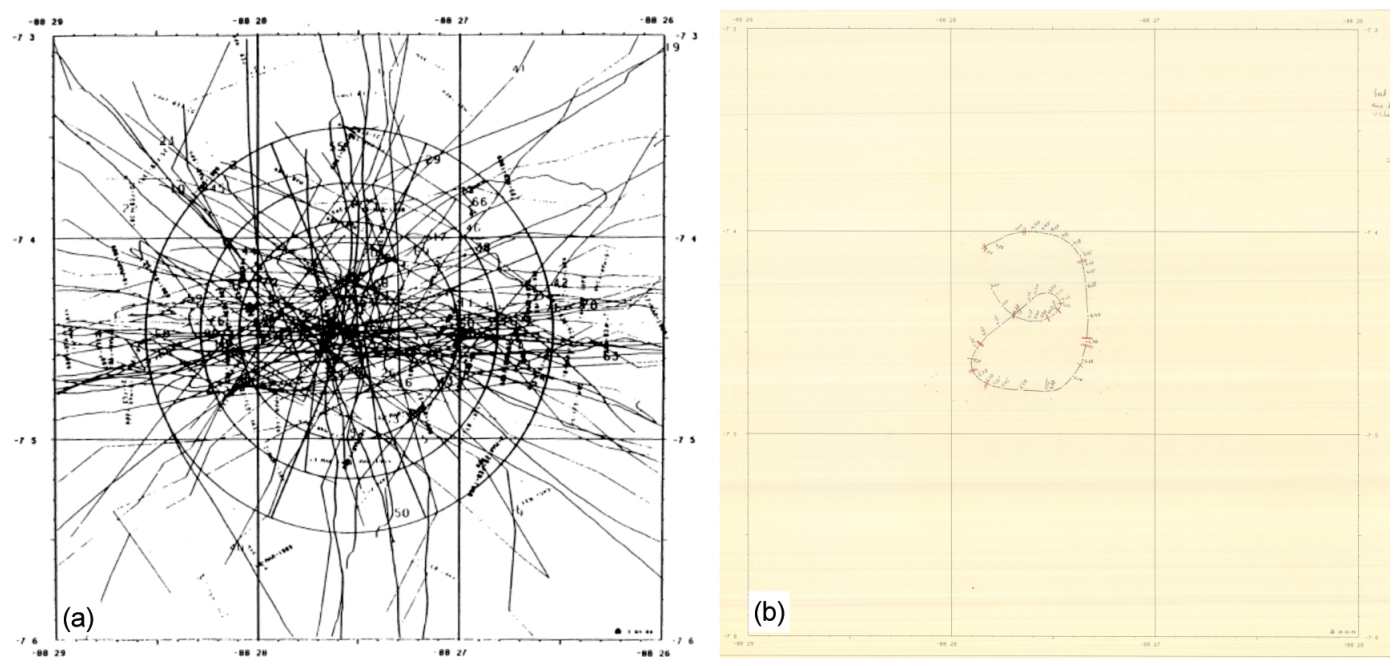

Figure 1. Legacy data from the first cruise (SO61) to the DEA: (a) reported location of the disturbance tracks in 1989 (modified from Thiel and Schriever, 1989); (b) print of the navigation records of OFOS009 during SO061.

Schriever and Thiel, 1992), SO106 (seven surveys; Schriever et al., 1996) and SO242 (18 surveys; Boetius, 2015; Greinert, 2015). Ship-based ultra-short baseline underwater navigation (USBL) was used for OFOS deployments during almost all cruises with lower accuracy during three of the initial cruises (SO61, 77, 106); it failed during SO64 (Schriever, 1990).

\subsubsection{Data description/working area}

The working area of cruise SO242 includes the DEA in the centre and extends about $10-13 \mathrm{~km}$ around it. Generally the area is located about $800 \mathrm{~km}$ west of the Peruvian coast and about $700 \mathrm{~km}$ south of the Galápagos Islands (Fig. 2a). NS-striking graben and horst structures can be seen throughout the entire area, corresponding to the highest slope angles of up to $36^{\circ}$ (Fig. B3b in Appendix B); they are related to the tectonic setting of the study site on the Nazca Plate which originates from the East Pacific Rise (Melchior, 2017). Within the working area the water depth varies between 4300 and $3850 \mathrm{~m}$ (Fig. 2b), with the minimum water depth corresponding to the summit of a rough sloping ( $>30^{\circ}$ slope angle, Fig. B3b) seamount (rising $\sim 200 \mathrm{~m}$ ) north of the DEA (Melchior, 2017). West of the summit the terrain drops along one of the N-S-striking graben structures with two lower seamounts of about $100 \mathrm{~m}$ height. About $18 \mathrm{~km}$ to the SE of the DEA another larger seamount rises up to $3980 \mathrm{~m}$ water depth showing pit structures of tens of metres in depth and width as has been recently described for the wider region to be generally associated with hill crests (Melchior, 2017). In the very west of the working area a $\mathrm{N}-\mathrm{S}$-striking narrow ridge highlights again the tectonic nature of the area with another element of the graben and horst fault system in the area. Besides these dominating bathymetric features, the rest of the terrain shows smooth undulating elevations and basins of several tens of metres depth and a few kilometres width, with slope angles of $<10^{\circ}$.

The finer structure of these flatter parts is much better resolved in AUV-acquired MBES data (Abyss192-194). The gently sloping terrain exhibits up to $15 \mathrm{~m}$ high hill/ridge and basin structures in the DEA and the western part of the mapped area (Figs. 2c, B4a). In $99 \%$ of the DEA the maximum slope of the terrain is only $3^{\circ}$ (Fig. B4b) with generally NNW-SSE-striking morphological features. Parallel to these, $<1 \mathrm{~m}$ high and $20-40 \mathrm{~m}$ wide ripple structures extend from the centre of the DEA towards the north. The appearance of these features indicate ripple structures oriented parallel to the predominant bottom current direction in this area (Thiel and Schriever, 1989; Greinert, 2015) and are further described below within this section. In the NE the terrain rises distinctly, forming up to $50 \mathrm{~m}$ high summits (Figs. 2c, B4a, B3). Within this mountain area an approximately $50 \mathrm{~m}$ deep circular crater structure can be seen (Fig. 2c) that is surrounded by steep slopes of up to $\sim 50^{\circ}$ (Fig. B4b). Within the crater two $\sim 10 \mathrm{~m}$ high conical hills consist of pillow basalts (revealed by OFOS footage; SO242-1_\#135_OFOS6), as a result of subrecent volcanism in the area (see Devey et al., 2020).

Using the AUV side-scan sonar (SSS) an area of $4 \mathrm{~km} \times 3.5 \mathrm{~km}$ with the DEA in the centre was mapped (Fig. 3). The acoustic signals captured a significant number of the plough tracks, which appear darker in the SSS map, representing a lower backscatter. Three dark distinct patches between 140 and $200 \mathrm{~m}$ in size are apparent within the sidescan data, indicating softer substrate within these structures that bathymetrically represent sediment-filled local basins of $\sim 5 \mathrm{~m}$ depth with a rather horizontal sea floor. The MBES backscatter and side-scan sonar data of the NNW-SSEstriking channel structures indicate deposition of softer sedi- 


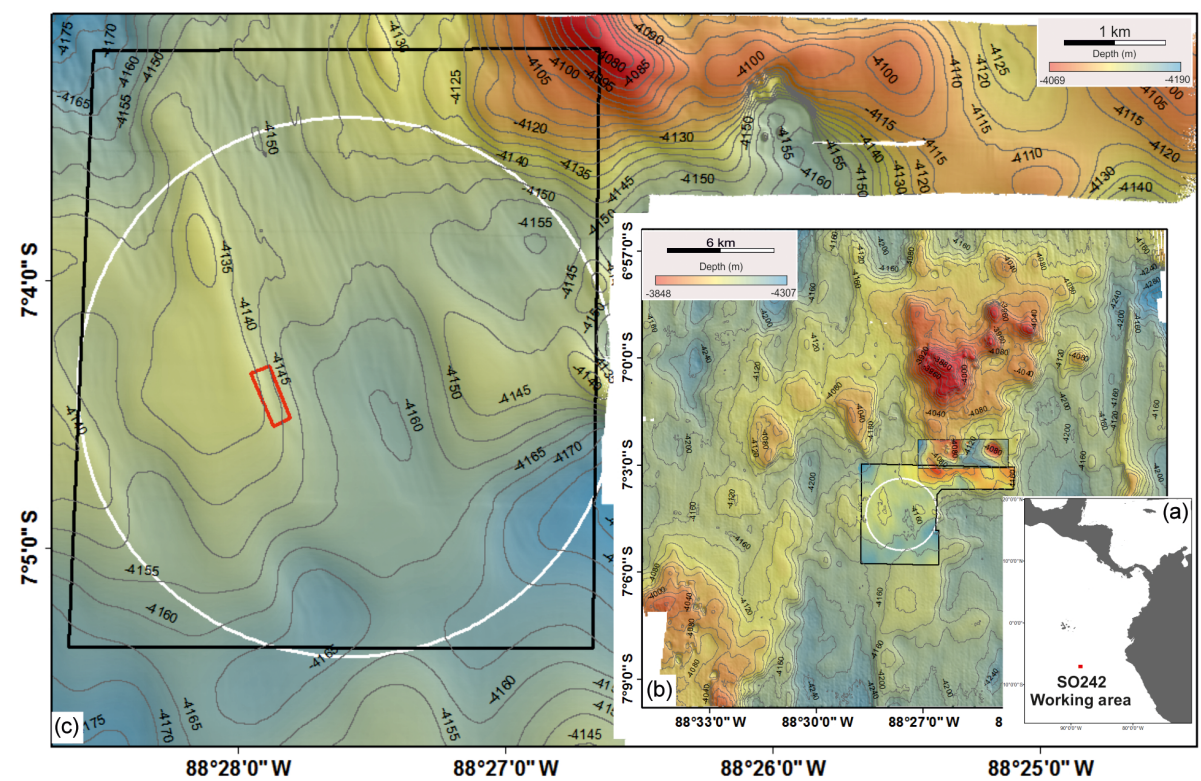

Figure 2. (a) Location overview of the DISCOL area (red square; coastline shape file from Wessel and Smith, 1996). (b) Ship-acquired bathymetric map of the working area from SO242 (white circle marks the DEA; black polygons mark the area mapped by the AUV). (c) AUV-acquired bathymetric map covering the DEA and a part of the hilly area NE of the DEA (merged from Abyss192 - SO242/1_047-1; Abyss 193 - SO242/1_060-1; Abyss194 - SO242/1_069-1); black polygon indicates the SSS-mapped area; white circle marks the DEA; red rectangle marks the location of the AUV-acquired photomosaic (Fig. B2).

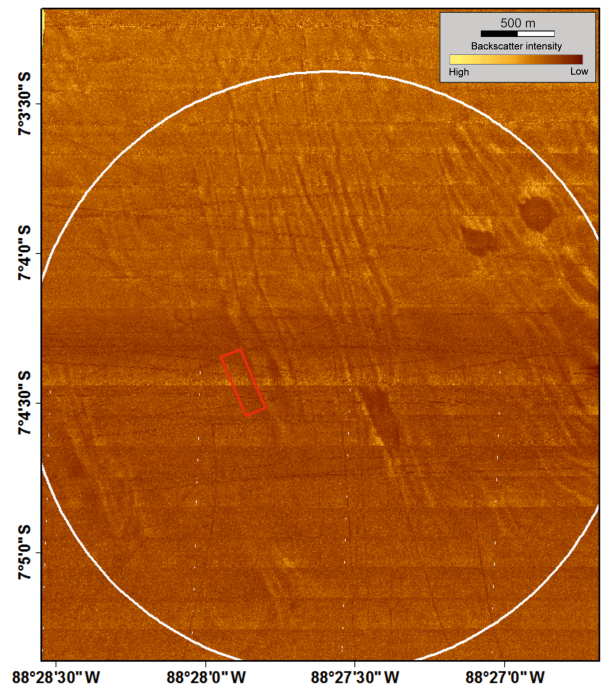

Figure 3. AUV-acquired SSS map (resolution $50 \mathrm{~cm}$ ) including the DEA (white circle); bright colours indicate high backscatter signals, and dark colours indicate low backscatter signals; red rectangle indicates the location of the photomosaic (Fig. B2).

ment within the depressions. The channel structures are oriented parallel to the prevailing strong bottom current direction within the area towards the NNW (Thiel and Schriever, 1989; Schriever and Thiel, 1992), and the undulating shape of the structures indicates a generation by a flow regime and not by tectonic activities, which would appear straighter.
We assume that bottom currents are channelized through the local trough around the rising terrain towards the NE and may cause turbulent flows which eventually cause furrowing. This process has also been described in the deep ocean with a dominant strong bottom current flow between 5 and $20 \mathrm{~cm} \mathrm{~s}^{-1}$ (Flood, 1983), which is given in the DEA, and hence this process could have formed these structures.

\subsection{Geo-referencing of AUV data sets}

AUV operation in great water depth suffers from inaccurate positioning of acquired data sets. Underwater positioning is typically determined using hydro-acoustic techniques as ultra-short baseline (USBL, measurement between the ship and the AUV) or long-baseline systems (LBL, triangulation of the AUV using sea-floor-deployed transponders). The AUV Abyss navigates autonomously using a combination of different navigational methods (Linke and Lakschewitz, 2016). During our studies LBL navigation was only used to set an accurate starting position of the AUV at the beginning of each survey after arriving at the sea floor. No additional LBL fixes were considered as this often results in abrupt track corrections that cause unwanted artefacts, particularly in SSS data. Instead, navigation after the initial LBL fix relied on Doppler velocity log (DVL) data, inertial navigation sensors and dead reckoning data fusion as supplied by the AUV system (Linke and Lakschewitz, 2016). Typically, such navigation is prone to slow drifts, which over the course of an entire mission (up to $20 \mathrm{~h}$ operation time) can 


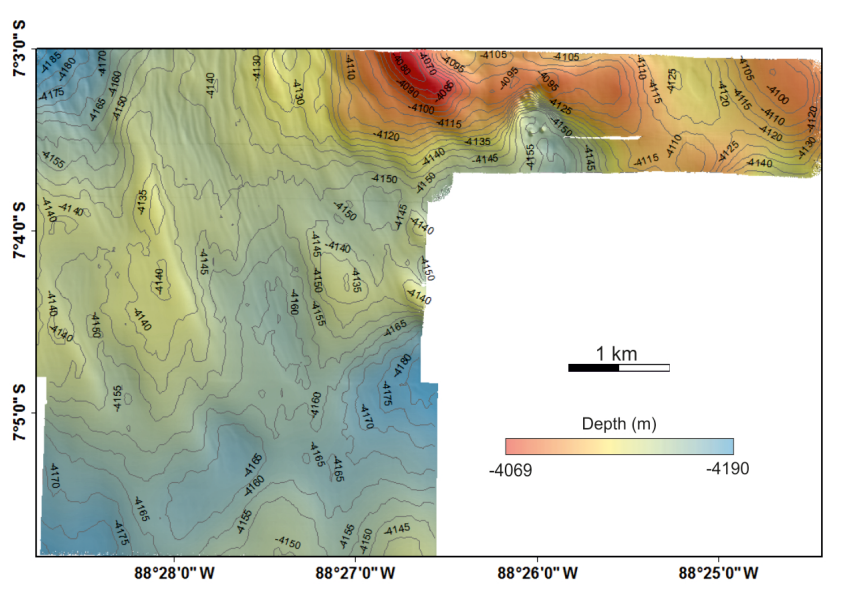

Figure 4. AUV-based bathymetry after alignment to the ship-based bathymetry. The plotted contour lines are the $5 \mathrm{~m}$ contours of the ship-obtained MB data set.

add up to offsets of several tens or hundreds of metres. These navigational shifts need to be derived and corrected during processing when comparing or combining several different data sets such as MBES, SSS, imagery of the AUV, imagery of OFOS and ship-based bathymetry.

To achieve the best possible alignment and absolute georeferencing, the ship-based EM122 bathymetric data with a spatial resolution of $38 \mathrm{~m}$ were taken as the absolute reference layer (Fig. C1 in Appendix C). The AUV bathymetric data with a spatial resolution of $2 \mathrm{~m}$ were resampled to match the $38 \mathrm{~m}$ resolution enabling a direct grid comparison (e.g. grid subtraction, Fig. E1 in Appendix E) and correction of vertical and lateral offsets of the AUV bathymetric grid relative to the ships' data layer. Using $5 \mathrm{~m}$ contour lines to visualize morphological features in the area, the $38 \mathrm{~m}$ AUV bathymetry was shifted/stretched manually onto the EM122 data (Fig. 4). Subsequently, the high-resolution AUV bathymetric digital terrain model was shifted in the same way using the ArcGIS 10.2 Georeferencing Toolbox for geographic corrections (contour lines were derived with the Spatial Analyst Toolbox and grids were subtracted to see $z$ offsets using the Raster Calculator function). Figure 4 shows the highresolution AUV bathymetry with the contour lines derived from the ship-based bathymetric grid to visualize the accordance of both data sets after the alignment.

The SSS map was geo-referenced relative to the AUV MBES data using a number of disturbance tracks, visible in the bathymetry (Fig. 5a, b and c) and the SSS data (Fig. 5d), and three prominent Mn-nodule-free depressions, which appear distinctly dark in the SSS map (Fig. 5c), as anchor features.

Based on the same structures, the photomosaics of the DEA could be aligned to the SSS map (Fig. 5e). Finally, visually detectable sampling locations of $\mathrm{BC}$, gravity corer (GC) or MUC impacts were used to validate the accuracy of

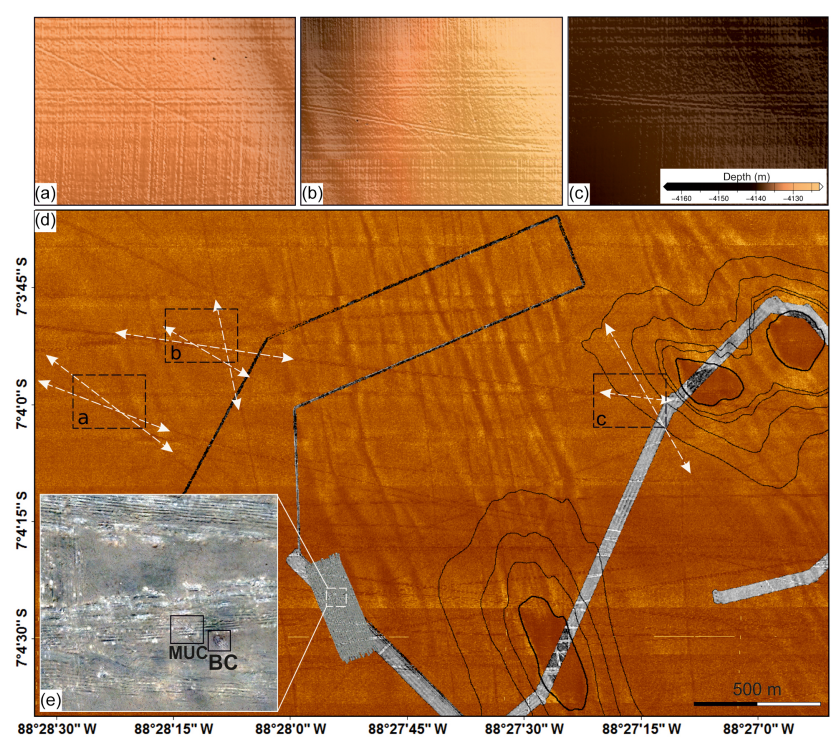

Figure 5. Plough marks visible in the highly resolved bathymetry (a, b, c) and the SSS map (d), as well as three characteristically shaped depressions visible in both data sets (d, black lines mark local $1 \mathrm{~m}$ contours), were used for the alignment of AUV MB and SSS data (see Fig. C2 for a larger section of the AUV MB map). The mosaics from AUV-acquired sea floor images (grey coloured in $\mathbf{d}$ ) were linked to the SSS map based on the same structures. The elongated photo survey is coloured by Mn nodules per square metre (Schoening et al., 2017) within the photos where the nodule-free areas appear distinctly dark; this was used for the alignment of the different data sets along the three "dark patches". Sampling locations visible in the photographs (e) function as anchor points to evaluate the referencing accuracy by the comparison with their USBL position.

the geo-referencing by comparison with their actual USBL positions (see Appendix D for details).

\subsection{Position and age sequence of disturbance tracks}

Disturbance tracks visible in SSS data (Fig. 5d) were manually digitized using functionalities of ArcGIS. Each track was given a unique identifier and was assigned to one of four classes reflecting the general orientation of the respective track: $\mathrm{H}$ for $\mathrm{E}-\mathrm{W}$-orientated tracks, D for NW-SE- and NE-SW-orientated tracks, $\mathrm{V}$ for $\mathrm{N}-\mathrm{S}$-orientated tracks, and $\mathrm{P}$ for non-continuous tracks and track segments (H: horizontal; D: diagonal; V: vertical; P: parts of tracks; Fig. 6; Table 1). The track IDs were arbitrarily given during the digitizing and were not renamed after the sequencing; thus the numbers do not reflect the age sequencing. During the digitizing it occurred that some of the tracks labelled as "P" for "parts" are as long as others assigned to one of the "entire track groups (V, H, D)", due to subsequent extension after further investigations. Because of this there is no clear definition when tracks are labelled P; however, $\mathrm{P}$ tracks are typically shorter than $1200 \mathrm{~m}$. 
Table 1. Identified plough tracks including the number of intersections and the absolute age with respect to the disturbance phase (PFEG2PFEG11). Track ID numbers are arbitrary and do not indicate any sequence; numbers were given during the digitalization.

\begin{tabular}{|c|c|c|c|c|c|}
\hline No. & Sequence number & Track_ID & Number of intersections & PFEG & Length (in metres) \\
\hline 1 & 1 & D01 & 53 & 2 & $4746.47^{*}$ \\
\hline 2 & 2 & D09 & 24 & 2 & $2866.55^{*}$ \\
\hline 3 & 3 & V02 & 43 & 2 & 3411.77 \\
\hline 4 & 4 & D07 & 33 & 2 & $3281.15^{*}$ \\
\hline 5 & 5 & $\mathrm{P} 01$ & 1 & 2 & $1013.31^{*}$ \\
\hline 6 & 6 & V03 & 14 & 2 & $1559.89^{*}$ \\
\hline 7 & $7-29$ & D20 & 31 & $3 / 4 / 5$ & $3580.93^{*}$ \\
\hline 8 & $7-30$ & D05 & 6 & $3 / 4 / 5$ & $1608.99^{*}$ \\
\hline 9 & $7-31$ & D08 & 22 & $3 / 4 / 5$ & $2465.54^{*}$ \\
\hline 10 & $7-31$ & P02 & 5 & $3 / 4 / 5$ & 957.88 \\
\hline 11 & $7-32$ & H07 & 15 & $3 / 4 / 5$ & $1673.07^{*}$ \\
\hline 12 & $7-32$ & H16 & 25 & $3 / 4 / 5$ & $2738.12^{*}$ \\
\hline 13 & $7-32$ & $\mathrm{H} 21$ & 28 & $3 / 4 / 5$ & $3538.1^{*}$ \\
\hline 14 & $7-32$ & $\mathrm{P} 10$ & 5 & $3 / 4 / 5$ & $584.55^{*}$ \\
\hline 15 & $7-38$ & P17 & 7 & $3 / 4 / 5 / 6$ & 1117.16 \\
\hline 16 & $7-46$ & $\mathrm{P} 27$ & 3 & $3 / 4 / 5 / 6 / 7$ & 170.68 \\
\hline 17 & $7-46$ & P31 & 1 & $3 / 4 / 5 / 6 / 7$ & 147.82 \\
\hline 18 & $7-46$ & $\mathrm{P} 30$ & 7 & $3 / 4 / 5 / 6 / 7$ & 359.03 \\
\hline 19 & $7-46$ & P29 & 9 & $3 / 4 / 5 / 6 / 7$ & 584.54 \\
\hline 20 & $7-46$ & P19 & 4 & $3 / 4 / 5 / 6 / 7$ & 267.84 \\
\hline 21 & $7-46$ & $\mathrm{P} 21$ & 2 & $3 / 4 / 5 / 6 / 7$ & $766.90^{*}$ \\
\hline 22 & $7-46$ & $\mathrm{P} 22$ & 1 & $3 / 4 / 5 / 6 / 7$ & 379.54 \\
\hline 23 & $7-46$ & P03 & 1 & $3 / 4 / 5 / 6 / 7$ & $831.79^{*}$ \\
\hline 24 & $7-45$ & P05 & 7 & $3 / 4 / 5 / 6 / 7$ & $1015.19^{*}$ \\
\hline 25 & $7-46$ & P07 & 7 & $3 / 4 / 5 / 6 / 7$ & 472.93 \\
\hline 26 & $7-46$ & D04 & 2 & $3 / 4 / 5 / 6 / 7$ & $1597.6^{*}$ \\
\hline 27 & $8-30$ & D21/P04 & 18 & $3 / 4 / 5$ & $1915.45^{*} / 552.3$ \\
\hline 28 & $8-46$ & P06 & 2 & $3 / 4 / 5 / 6 / 7$ & $828.98^{*}$ \\
\hline 29 & $8-31$ & D06 & 3 & $3 / 4 / 5$ & $1177.81^{*}$ \\
\hline 30 & $9-31$ & $\mathrm{H} 26$ & 22 & $3 / 4 / 5$ & $2624.92^{*}$ \\
\hline 31 & $10-32$ & $\mathrm{H} 02$ & 18 & $3 / 4 / 5$ & $2325.01^{*}$ \\
\hline 32 & $10-33$ & D18 & 39 & $3 / 4 / 5$ & $3776.48^{*}$ \\
\hline 33 & $18-46$ & $\mathrm{P} 15$ & 4 & $4 / 5 / 6 / 7$ & $626.25^{*}$ \\
\hline 34 & $18-46$ & P11 & 3 & $4 / 5 / 6 / 7$ & $231.42^{*}$ \\
\hline 35 & $18-46$ & P14 & 3 & $4 / 5 / 6 / 7$ & 500.08 \\
\hline 36 & 20-39 & D14 & 41 & $4 / 5 / 6$ & $3721.02^{*}$ \\
\hline 37 & $20-39$ & D19 & 11 & $4 / 5 / 6$ & $895.11^{*}$ \\
\hline 38 & $22-41$ & $\mathrm{H} 22$ & 29 & $4 / 5 / 6$ & $2775.6^{*}$ \\
\hline 39 & $22-44$ & $\mathrm{H} 25$ & 25 & $4 / 5 / 6$ & $3610.85^{*}$ \\
\hline 40 & $23-43$ & D12 & 47 & $4 / 5 / 6$ & $4163.09^{*}$ \\
\hline 41 & $23-45$ & $\mathrm{H} 24$ & 18 & $4 / 5 / 6 / 7$ & $2986.35^{*}$ \\
\hline 42 & 24-44 & D13 & 39 & $4 / 5 / 6$ & $3294.63^{*}$ \\
\hline 43 & $25-45$ & D16 & 39 & $4 / 5 / 6 / 7$ & $3949.62^{*}$ \\
\hline 44 & $25-45$ & D10 & 50 & $4 / 5 / 6 / 7$ & $4411.18^{*}$ \\
\hline 45 & $25-46$ & $\mathrm{P} 23$ & 3 & $4 / 5 / 6 / 7$ & 212.86 \\
\hline 46 & $26-46$ & D17 & 41 & $4 / 5 / 6 / 7$ & $3626.51^{*}$ \\
\hline 47 & $47-48$ & H17 & 29 & 8 & $2782.15^{*}$ \\
\hline 48 & $47-48$ & $\mathrm{H} 20$ & 22 & 8 & 1717.86 \\
\hline 49 & $49-50$ & D02 & 50 & 8 & $5248.51^{*}$ \\
\hline 50 & $49-50$ & D03 & 50 & 8 & 5099.99* \\
\hline 51 & 51 & D11 & 26 & 8 & 2224.16 \\
\hline 52 & 52 & V01 & 47 & 8 & $4290.25^{*}$ \\
\hline 53 & 53 & H03 & 26 & 8 & $3545.04^{*}$ \\
\hline 54 & 54 & H01 & 26 & 8 & $3486.25^{*}$ \\
\hline 55 & 55 & H06 & 32 & 8 & $3524.81^{*}$ \\
\hline
\end{tabular}


Table 1. Continued.

\begin{tabular}{|c|c|c|c|c|c|}
\hline No. & Sequence number & Track_ID & Number of intersections & PFEG & Length (in metres) \\
\hline 56 & 56 & D15 & 42 & 8 & $3598.8^{*}$ \\
\hline 57 & 57 & V10 & 45 & 9 & $4219.36^{*}$ \\
\hline 58 & 58 & V08 & 46 & 9 & $3800.9^{*}$ \\
\hline 59 & 59 & V07 & 47 & 9 & $3943.95^{*}$ \\
\hline 60 & 60 & V06 & 48 & 9 & $4299.11^{*}$ \\
\hline 61 & $61-63$ & V04 & 46 & 9 & $4247.57^{*}$ \\
\hline 62 & $61-63$ & V09 & 40 & 9 & $3432.81^{*}$ \\
\hline 63 & $61-63$ & V05 & 49 & 9 & $4238.12^{*}$ \\
\hline 64 & $64-65$ & P16 & 3 & 9 & 219.15 \\
\hline 65 & $64-65$ & V11 & 41 & 9 & $3889.04^{*}$ \\
\hline 66 & $66-67$ & H18 & 33 & 10 & $3513.86^{*}$ \\
\hline 67 & $66-67$ & H11 & 32 & 10 & $3548.1^{*}$ \\
\hline 68 & $68-71$ & H10 & 26 & $10 / 11$ & $3480.55^{*}$ \\
\hline 69 & $68-71$ & H13 & 31 & $10 / 11$ & $3559.03^{*}$ \\
\hline 70 & $68-71$ & H09 & 27 & $10 / 11$ & $3496.72 *$ \\
\hline 71 & $68-71$ & $\mathrm{H} 23$ & 32 & $10 / 11$ & $3512.36^{*}$ \\
\hline 72 & $72-74$ & H19 & 28 & 11 & $3264.1^{*}$ \\
\hline 73 & $72-74$ & H04 & 29 & 11 & 3468.02 \\
\hline 74 & $72-74$ & H08 & 30 & 11 & $3505.65^{*}$ \\
\hline 75 & $75-77$ & H05 & 25 & 11 & $3946.72^{*}$ \\
\hline 76 & $75-77$ & H12 & 34 & 11 & $3089.88^{*}$ \\
\hline 77 & $75-77$ & $\mathrm{H} 28$ & 25 & 11 & $3524.09^{*}$ \\
\hline 78 & $78-80$ & H14 & 18 & 11 & $2121.69^{*}$ \\
\hline 79 & $78-80$ & H15 & 31 & 11 & $3501.81^{*}$ \\
\hline 80 & $78-80$ & $\mathrm{H} 27$ & 24 & 11 & $3527.22^{*}$ \\
\hline 81 & - & P13 & 0 & - & 289.68 \\
\hline 82 & - & P18 & 1 & - & $102.48^{*}$ \\
\hline 83 & - & $\mathrm{P} 20$ & 0 & - & 227.23 \\
\hline
\end{tabular}

* Tracks extend beyond the limits of the SSS data.

Generally during the ploughing in 1989 several tracks were undertaken during one deployment of the plough (station name PFEG-1 to PFEG-11; PFEG1 was a gear handling test a few nautical miles south of the DEA). After the first two groups PFEG2 and PFEG3, OFOS dives OFOS009 and OFOS010 were conducted during SO61 and the photo and video material collected during these two OFOS dives could be examined for track occurrences. The track orientation was determined from each sea floor image and matched to the track orientation on the SSS map considering the course over ground (COG) and heading of the OFOS (Fig. 7) to distinguish the correct plough track. This way and considering the log files from cruise SO61, which gave an idea about rough course and location of the ploughs, the tracks corresponding to the first two plough groups (15 tracks) could be identified. Considering photo and video material from remotely operated vehicle (ROV) (GEOMAR Helmholtz-Zentrum für Ozeanforschung, 2017), AUV and OFOS surveys and the SSS data, intersections were visually examined to establish a relative age succession between the investigated tracks (Fig. 8).
For some intersections the sequence could not directly be established and was inferred considering the relative track age information of other intersecting tracks (Fig. 8). Unfortunately, this workflow could not be applied for the later groups of tracks (PFEG4 to PFEG11) since they were not directly followed by an OFOS survey. Thus the track density until the next OFOS observation became too high, and, considering the navigation uncertainties, an unambiguous assignment of the tracks is not possible. The reconstruction of the age succession of all tracks was finally carried out using an $84 \times 84$ matrix (including 60 identified tracks and 24 track segments, Table F1 in Appendix F) where all observed crossings were included. Logical process of elimination and crossreferencing of individual tracks relative to all other tracks in combination with their position and the reconstructed ships' navigation during the time of the experiment (Fig. 1a) were performed. Based on this, the tracks were assigned to their respective PFEG and to track IDs (Table 1).

\subsection{Reconstructing the impact of the resettled plume}

The initial impact of the plough tracks is given through the mixing (ploughing) of the top 20 to $30 \mathrm{~cm}$ of the sediment 


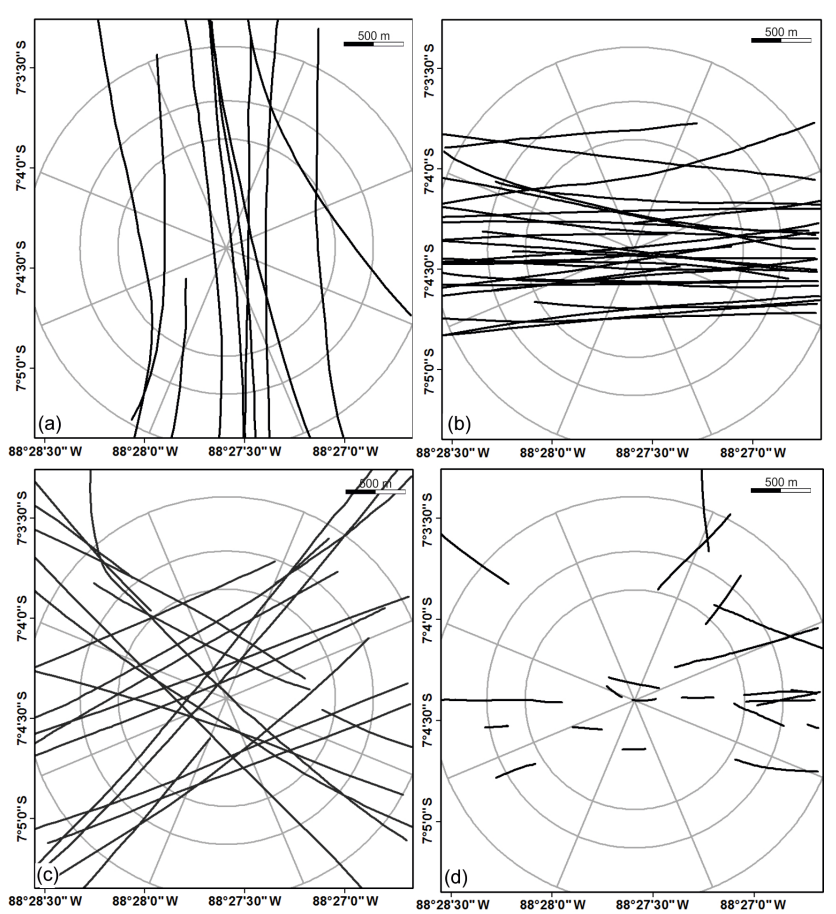

Figure 6. Identified plough tracks classified and named after their orientation within the DEA (grey circled area); (a) 11 vertical tracks "V"; (b) 28 horizontal tracks "H"; (c) 21 diagonal tracks "D"; (d) 24 partial tracks/segments "P".

and the related suspension of sediment into the bottom water (Foell et al., 1990). Nodules were not removed from the sea floor but ploughed under (Thiel and Schriever, 1989). The resedimentation of the initiated sediment plume is considered the secondary impact. For reconstructing the initial impact and the proximal (visible in images) sediment blanketing, the course of the plough tracks was used in combination with bottom current information recorded during the time of the experiment to establish a disturbance intensity map (including initial and secondary impact). Also considering the plume deposition information from other BIEs (Table A1) and the recent study by Peukert et al. (2018), the qualitative sediment blanketing thickness within the DEA was determined based on the following assumptions and set parameters. Each track was assumed to have a width of $8 \mathrm{~m}$, not considering the possible handling problems with the plough harrow (e.g. being towed only on the side, short loss of bottom contact; Thiel and Schriever, 1989). The intensity of the disturbance was assumed to be the highest within and close to the tracks, and the sediment blanketing thickness was assumed to decrease with increasing distance off the track. Studies from other BIEs showed visual sediment blanketing distances between 70 and $150 \mathrm{~m}$ in current direction away from the track. It is assumed that the majority of the resuspended sediment (about $90 \%$ ) resettled over this distance (Lavelle et al., 1981; Peukert et al., 2018).
The main factors controlling the redeposition are current speed and direction and particle settling velocity with the last being describable as a function of the particle size according to Stoke's law and the method described by McCave (1984; Jankowski et al., 1996). The sediments within the DEA are composed of layered clayey silts or silty clays, with a sand fraction of ca. $5 \%$ consisting of foraminiferous residues and shell fragments (Grupe et al., 2001). According to Lavelle et al. (1981), Schriever et al. (1996) and Becker et al. (2001) the stirred-up sediment mixture induced flocculation and aggregation of particles, causing a very rapid resedimentation $\left(\geq 1 \mathrm{~cm} \mathrm{~s}^{-1}\right.$ ) of the plume within the first $20 \mathrm{~m}$ away from the track. The latest research on mining-induced sediment plume behaviour also indicated a near-track heavy sediment blanketing (Gillard et al., 2019). The sediment blanketing decreases as a function of reduced particle settling velocities as finer particles dominate the plume composition and stay longer in suspension (Lavelle et al., 1981).

Bottom current direction and velocity determine the direction of the resedimentation area and sediment spreading (Lavelle et al., 1981; Jankowski et al., 1996; Greinert, 2015). Bottom currents in the central Pacific are reported to be distinctly different even at locations only a few kilometres apart (Robinson and Kupferman, 1985). Several measurements in the DISCOL area revealed a predominantly northern to northwestern direction, with maximum current speeds of $17 \mathrm{~cm} \mathrm{~s}^{-1}$ (Thiel and Schriever, 1989; Schriever and Thiel, 1992) indicating a transport of the resuspended particles primarily in this direction. The undertaken measurements showed that the currents in the DEA alternate between strong $\left(>5 \mathrm{~cm} \mathrm{~s}^{-1}\right)$ and quasi-unidirectional currents towards the NNW and weaker currents $\left(<1-3 \mathrm{~cm} \mathrm{~s}^{-1}\right)$ with greater directional variability (Klein, 1993, 1996). This variability has also been observed during the first cruise SO61 to the DISCOL area (Thiel and Schriever, 1989), with the "strong" current regime occurring during the first leg (February 1989) and the creation of PFEG1 to 7 and the weaker currents towards the end of the second leg (March 1989) and the creation of PFEG8 to 11, where the currents showed semidiurnal change of current direction from predominantly NNE to predominantly SSE. This certainly affected the sediment plume dispersal.

Since no information about the amount of resuspended material is available, the impact is reconstructed qualitatively using values resembling disturbance intensity between 1 within the disturbance tracks and 0.1 , representing the deposition of $90 \%$ of the resuspended material at the maximum distance of the proximal disturbance. With regards to other impact monitoring results from large-scale disturbances (e.g. Lavelle et al., 1981, Table A1) and the results of small-scale disturbance experiments conducted during SO239 (Martinez-Arbizu and Haeckel, 2015; Peukert et al., 2018), SO242/1 (Greinert, 2015) and SO242/2 (Boetius, 2015), the maximum distance affected by sediment blanketing was assumed to be $120 \mathrm{~m}$ with and $20 \mathrm{~m}$ against the cur- 


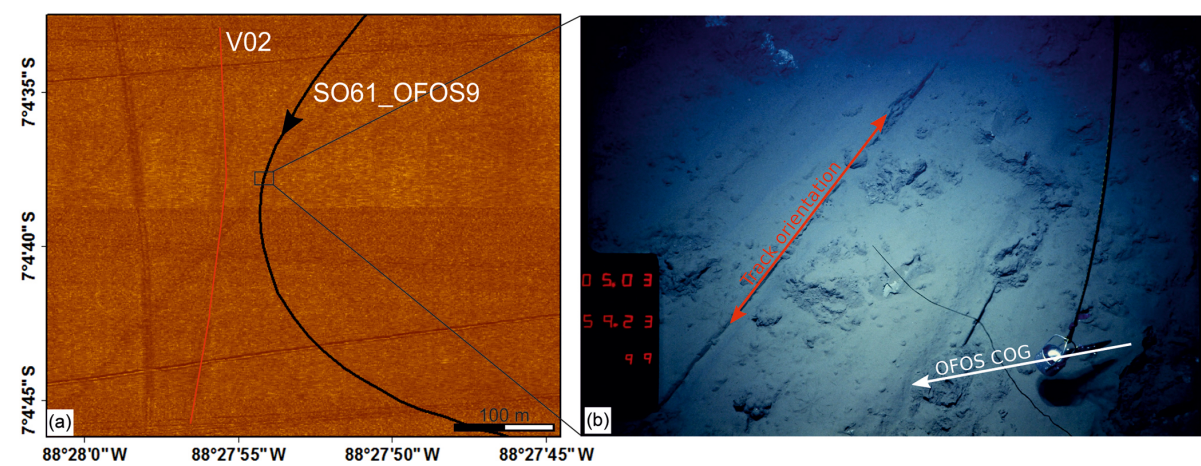

Figure 7. Identifying the very first disturbance tracks (PFEG2) using the reconstructed instrument navigation (SO061_OFOS9) plotted on the SSS map of the DEA (a) and camera data collected during this survey (b) with respect to the track orientation and the previously determined relative age succession.
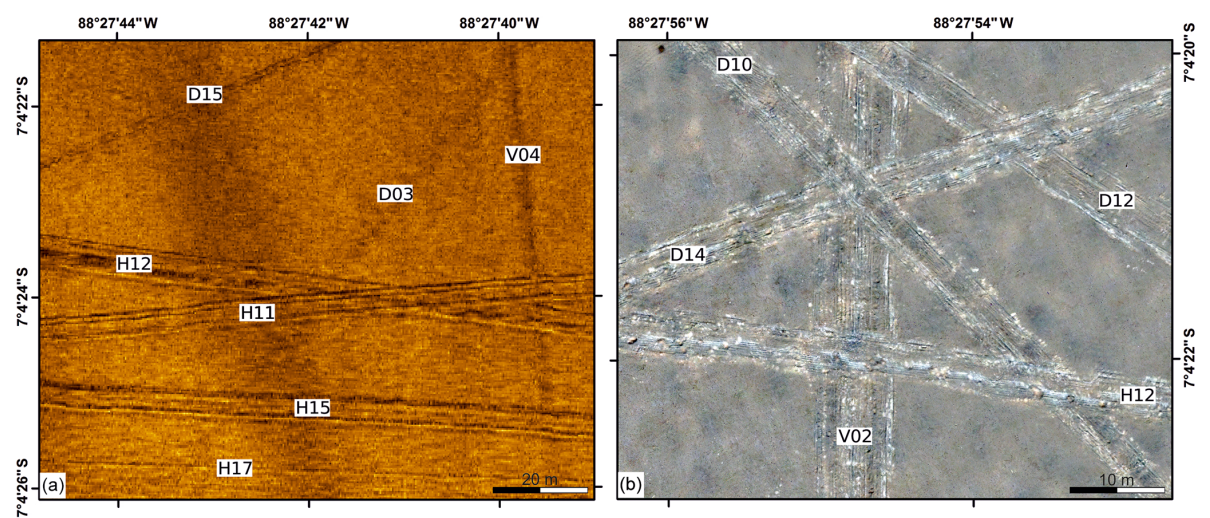

Figure 8. Establishing the relative age sequence based on intersections between two tracks from the SSS map (a) and sea floor photographs (b). Absolute age information can be derived from cross-referencing relative age information of more than two individual tracks (b). Here the age sequence of all shown tracks is $\mathrm{V} 02<\mathrm{D} 12<\mathrm{D} 14<\mathrm{D} 10<\mathrm{H} 12$.

rent direction for the strong current regime. These distribution values and a distribution direction of $334^{\circ}$ were set for PFEG 2 to 7 and all recognized parts of plough tracks which could not be assigned to a distinct PFEG. To account for the changing conditions during weaker bottom currents (PFEG 8 to 11 ), the distances were set to $100 \mathrm{~m}$ with and $30 \mathrm{~m}$ against the current direction. Based on the statistics of the current directions (Thiel and Schriever, 1989) during the creation of 31 recognized tracks of that period, the plough tracks were divided in two groups, one considering a NNE current (towards $18^{\circ}, 19$ tracks) and the other group considered a SSE current (towards $143^{\circ} ; 12$ tracks). Considering the semidiurnal current direction change, the assignment of the tracks to one of those groups was based on the estimation of the track creation time and duration in consideration of the length of one track and the speed of the ship while ploughing and the determined relative sequence of the single tracks.

For calculating the sediment plume deposition downcurrent and up-current (due to turbulence), the following simple function was used:
$y=e^{-\left(\frac{x}{R}\right)}$,

with $y$ representing the relative sediment thickness at distance $x$ from the disturbance track.

An exponential function was chosen to account for the effects of flocculation and aggregation of the resuspended sediment closer to the track. The factor $R$ was introduced to meet the assumption that $10 \%$ of the resuspended material remains in the water column and is redeposited at greater distances (Lavelle et al., 1981; Jankowski et al., 1996). This factor was considered for the particle transport with the prevailing bottom currents. Against the bottom currents, the resuspended material was assumed to completely resettle within either the first $20 \mathrm{~m}$ for strong currents or $30 \mathrm{~m}$ for weak currents. The relative sediment thickness was calculated in $0.8 \mathrm{~m}$ steps away from each disturbance track considering the above-mentioned current directions. The final blanketing map was produced by adding all relative sediment thicknesses within each square metre of the DEA area using the blockmean command in Generic Mapping Models (GMT, ar- 
gument -Ss to get the sum; Wessel et al., 2013) and producing an interpolated grid using the nearneighbor command. It is assumed that the plough intensity and sediment resuspension did not change as each plough track was created.

\section{Results}

\subsection{Geo-referencing of data sets}

Navigational offsets were detected between the different AUV missions with lateral offset between AUV and ship data of 30 to $80 \mathrm{~m}$ (Fig. 4). As AUV data sets from four different MBES surveys are used, a good geo-referencing of the completely compiled AUV data set on the ships' bathymetry was not possible. Therefore a focus for the best possible alignment was set to the DEA region with only three AUV data sets. To check for the improvement of the geo-referencing, the AUV bathymetry was subtracted from the ship-obtained data set at identical resolution (Fig. E1). Prior to shifting and stretching of the AUV grid, the depth differences showed a mean offset of $-9 \mathrm{~m}$. Thus $9 \mathrm{~m}$ was added to the entire AUV bathymetric grid to account for this absolute $z$ offset, and after shifting/stretching the difference between the AUV and ships' bathymetry showed the mean to be at $0 \mathrm{~m}$ depth difference with only a $\pm 0.5 \mathrm{~m}$ median range (Fig. E1).

As for the MBES data, the lateral offset between different SSS data surveys was not constant but varied between 40 and $50 \mathrm{~m}$. Geo-referencing the combined SSS map onto the AUV bathymetry showed offsets between 30 and $80 \mathrm{~m}$ that were corrected (Fig. G1 in Appendix G). The photomosaics, which could be aligned to the SSS map very accurately, show sampling locations that we compared to the USBL position during the time of sampling for validating the geo-referencing results (Fig. 9; Table G1 in Appendix G). The mean difference between the geo-referenced photomosaic sampling locations and those from the USBL navigation is $14 \mathrm{~m}$ (Table G1), whereas BC positions on average differ by $11 \mathrm{~m}$ and MUC positions differ by $19 \mathrm{~m}$. These values indicate the overall absolute accuracy of the navigation and geo-referencing that could be achieved. The accuracy decreases in the outer regions of the SSS data, as no additional information such as sea floor sampling locations or characteristic features is available.

\subsection{Plough tracks and their sequence}

Within the SSS map a total of 60 continuous tracks were identified and assigned to three different classes: V (11), H (28) and D (21) (Fig. 6). In addition, 24 track segments were found and represent the fourth class P (Fig. 6; Table 1). Some of these partial tracks were assigned to other track identifiers (Table 1), based on the same course, but this could not be accomplished for all of the segments.

\subsection{Estimation of the impacted area}

\subsubsection{Initial plough impact}

Based on the detected plough tracks (including the track segments) the directly impacted area is $1.9 \mathrm{~km}^{2}$, corresponding to approximately $19 \%$ of the DEA $\left(10.81 \mathrm{~km}^{2}\right)$ assuming a width of each individual disturbance track of $8 \mathrm{~m}$ (Thiel and Schriever, 1989) and a length of approximately $3 \mathrm{~km}$ within the DEA. This area agrees with the original estimate (ca. $20 \%$; Thiel and Schriever, 1989). However, this represents only an approximation of the disturbed area as the length of the tracks is variable and individual ones reach a length of up to $5 \mathrm{~km}$ and not all of the tracks could be identified to their complete extent. The disturbance tracks can clearly be observed to continue outside the DEA target circle of $2 \mathrm{nmi}$ in diameter, and the created impact on the ecosystem extends beyond the limits of the DEA and even beyond the area covered by the SSS data (Fig. 10). The total plough area from 1989 is thus not exactly known.

In comparison, the previously reported disturbance track locations and the observations from 2015 generally show the same trend with a high density of E-W-oriented tracks and fewer tracks with $\mathrm{N}-\mathrm{S}$ orientation (Fig. 10). The locations of individual disturbance tracks do not agree well, most likely because the plough tracks from 1989 were reconstructed from the ship position only (with a much lower accuracy than today) and an almost unknown distance between the ship and the towed plough (Thiel and Schriever, 1989).

\subsubsection{Secondary sediment deposition impact}

The derived sediment disturbance map of the DEA (Fig. 11) indicates the highest levels of disturbance within the centre (C sectors in Fig. 11) of the DEA coinciding with high densities of plough tracks and in the easternmost peripheral $(\mathrm{P}$ sectors in Fig. 11) sectors.

\section{Discussion}

\subsection{Geo-referencing}

The quality of geo-referencing different data layers towards each other highly depends on prominent morphological features that are detectable in all available data layers. The depth differences of more than $5 \mathrm{~m}$ between the ship- and AUVbased multibeam data after geo-referencing (marked red in Fig. E1) are related to two different AUV surveys, which seem to be inconsistent. However, the range of vertical depth deviation is still within the given depth resolution of the EM122 ship system (Kongsberg, 2007) of maximum 0.2\% of the water depth $(=\sim 8 \mathrm{~m})$.

The alignment of the SSS and optical data onto the AUV MBES data was reasonably easy due to the presence of the 

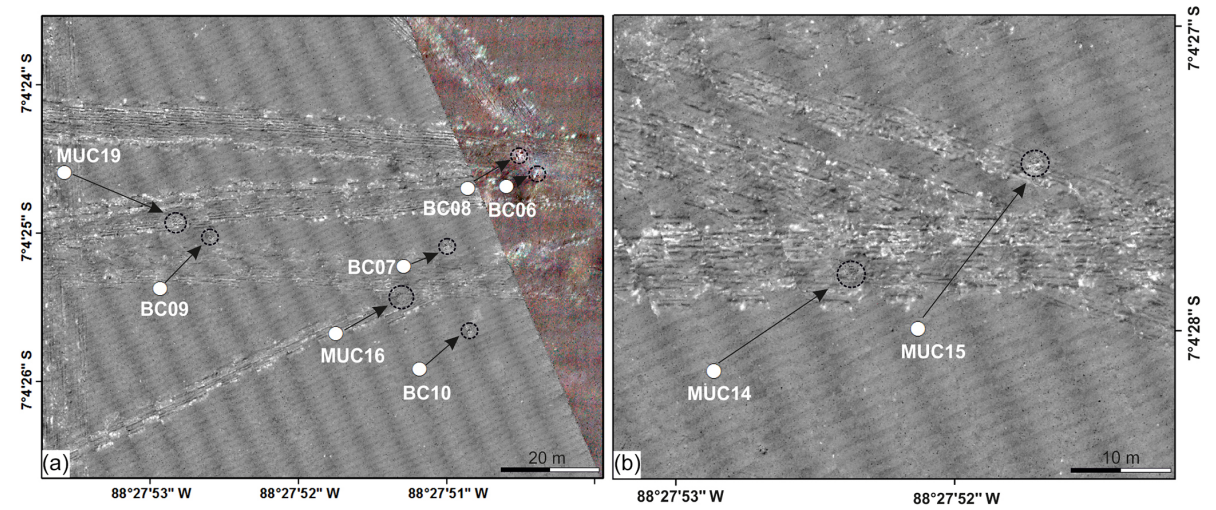

Figure 9. Determining the accuracy of the geo-referencing based on impact features of sea floor sampling during SO242/1; black arrows indicate the offset between the sampling positions determined using USBL (white dots) and imprint on the sea floor (black circled) after applying the geo-referencing method.

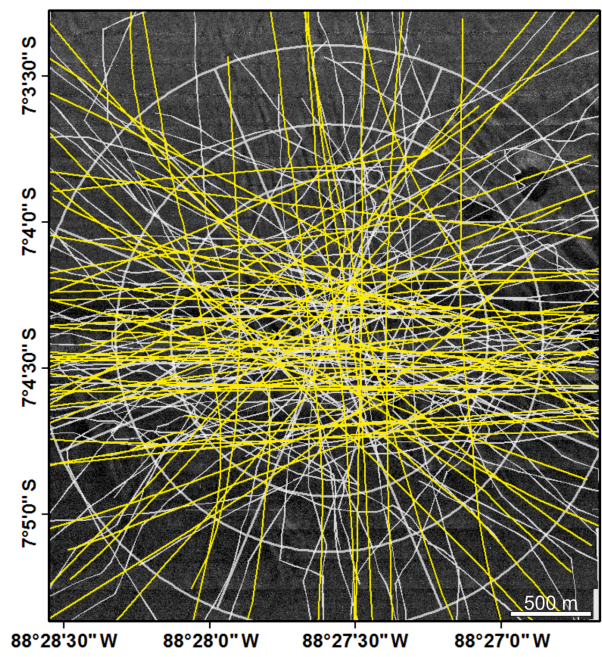

Figure 10. Logged in 1989 (light grey) and reconstructed (yellow) plough track positions (Thiel and Schriever, 1989) plotted on the updated geo-referenced AUV SSS map.

plough marks visible in all of the high-resolution data sets; this provided a sufficient number of anchor points over the entire area. A considerable shift of $80 \mathrm{~m}$ encountered during the geo-referencing highlights the importance of accurate navigation and being aware of these kinds of offsets and deviations between the different data sets. When detailed sampling is requested, especially in terms of smallscaled (tens of metres) habitat mapping, wrong navigation and geo-referencing will make analyses and correct interpretations impossible.

The remaining shift of $14 \mathrm{~m}$ between the USBL recorded sample positions and the position visible in the photomosaics (Fig. 9) is, for the given purpose, within an acceptable range. Regarding the punctual position of sampling compared to the lateral grid resolution of $38 \mathrm{~m}$ of the ship-obtained MBES data as the base of the geo-referencing, such an offset might be unavoidable without considerably more technical effort of sea-floor-based navigation systems that build a temporary reference system for all deployed gear. In our case the USBL transponder for the sampling gear was mounted $100 \mathrm{~m}$ (MUC) or $50 \mathrm{~m}$ (BC) above the gear on the wire, which might be already one source of error, if the rope most likely is not vertical above the sampling gear while this touches the bottom. Small, not completely correct evaluated static offsets between GPS and the USBL antenna as well as misalignments between the motion reference unit and USBL antenna might cause another problem that is difficult to evaluate without dedicated tests. Therefore the remaining range of 10 to $20 \mathrm{~m}$ deviation should be considered "normal" for sample interpretation and navigational accuracy between differently derived map and location data sets.

\subsection{Plough tracks and age succession}

About $77 \%$ of the reported disturbance tracks (60 out of 78) could be identified, most of them based on the SSS data (Sect. 2.4). The 24 track segments of class P might account for the missing 18 tracks (e.g. P04 has been assigned to D21, Table 1).

The high-resolution MBES data did not fully capture the disturbance tracks due to the small morphological differences between plough tracks and the surrounding sea floor (circa 15-30 cm; Boetius, 2015) and the internal structure of the plough marks. The reconstruction of the initial disturbance was mainly based on the SSS mapping because of the higher along-swath resolution of the SSS compared to the MBES data. The penetration depth of the plough harrow in combination with its very characteristic pattern facilitates the detection of the disturbance tracks. Morphological changes that are ensonified perpendicularly (tracks parallel to the AUV flight path) cause higher reflections of the emitted signal compared to perpendicular tracks to which the small ridges and valleys of a plough track are ensonified parallel 

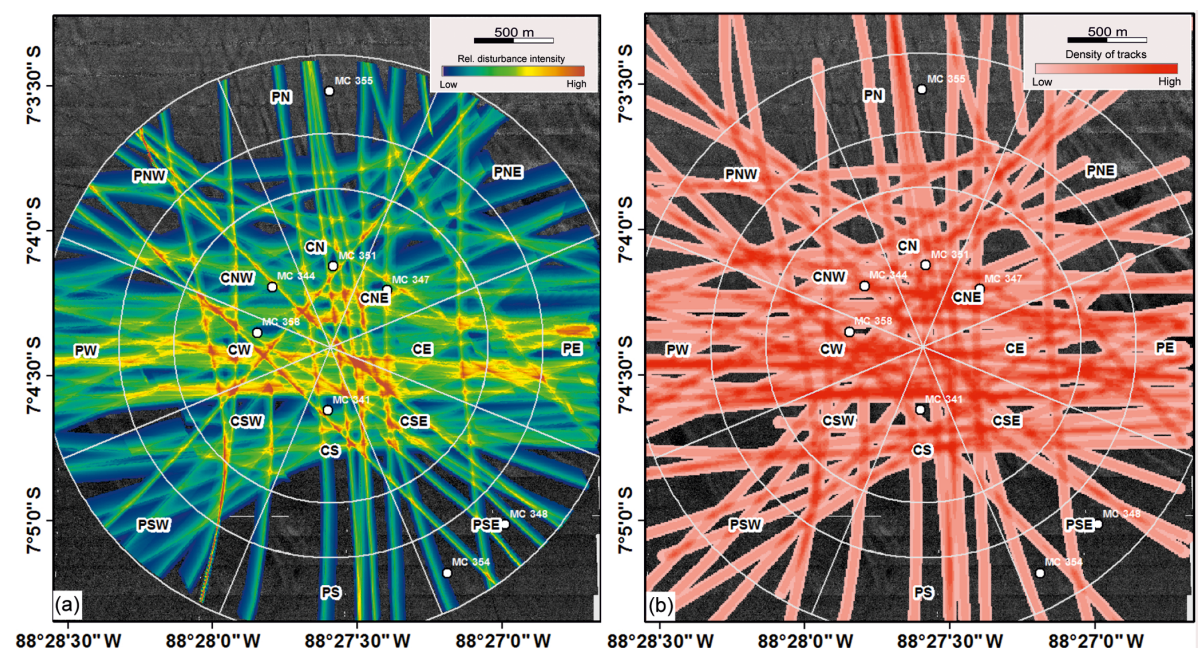

Figure 11. Relative disturbance intensity and track-density maps of the DEA with the different sectors defined in 1989 (after Thiel and Schriever, 1989; "C": centre; "P": peripheral). White dots indicate sampling stations from cruise SO77 (Schriever and Thiel, 1992) for XRAY sediment blanketing thickness analysis (results see Table H1 in Appendix H); (a) relative disturbance intensity map of the DEA representing the disturbance by the track itself ("initial impact") and the thickness of resettled plume sediments adjacent to the tracks ("secondary impact"). (b) Heat map representing the track densities per $8 \mathrm{~m} \times 8 \mathrm{~m}$ cell size indicating the relative plough disturbance levels within the DEA; the highest calculated density is set to $100 \%$ disturbance.

(Lurton, 2017). Thus some tracks can be seen more clearly in the SSS data than others, which also causes the sequence at some crossings to not be finally determined. The very first disturbance tracks are clearly visible within the SSS data, again indicating that the amplitude of the signal reflectance cannot be used as an indicator for their relative age. This becomes even more evident when comparing acoustic and optical data of the AUV. Some tracks that were barely visible in the SSS image (resolution: $0.5 \mathrm{~m}$ ) could be clearly detected in sea floor photographs. Following this, the most reliable data source to establish the relative age sequence is the image and video material recorded by the various devices (AUV, ROV, OFOS) deployed during SO242 and the OFOS data from the previous cruises. The different survey altitudes and operation plans influence the area that was covered by each instrument and the quality of the images (Greinert, 2015). The AUV photomosaics turned out to show the best results in resolving the age relation of multiple tracks even in highly disturbed areas within the DEA. There were a total of 9 AUV, 18 ROV and 57 OFOS surveys conducted within the DEA between 1989 and 2015. However, since the DEA was not entirely covered by visual investigations, it is possible that some tracks which were not detected by the SSS were also not seen with the optical devices.

In general, the age reconstruction was successful, where more than one data set was available. The plough tracks could be reconstructed with the highest amount of certainty for the very first and second sets of disturbance tracks (PFEG 2 and PFEG 3). The uncertainties within the sequence regarding the absolute ages, especially with later sets of tracks (PFEG 4-11), increase since they are mainly based on statis- tical information and the logical method of elimination (see Sect. 2.4).

\subsection{Disturbance levels in the DEA}

Mesoscale numerical sediment distribution modelling by Jankowski et al. (1996) and Jankowski and Zielke (2001) considering all plough tracks of the DEA experiment predicted blanketing of resettled material of $>100 \mathrm{~g} \mathrm{~m}^{-2}$ up to a distance of $2 \mathrm{~km}$. Due to the lack of data that measured the amount of resuspended sediment, actual mass values of the blanketing cannot be given for our near-field estimate approach. The settling velocity is also highly dependent on the sediment plume concentration (Gillard et al., 2019). As stated, only $90 \%$ of the sediment is assumed to settle immediately due to flocculation and aggregation, causing resettling of particles within proximal distances (Becker et al., 2001; Gillard et al., 2019). The changing current conditions over the course of the plough experiment, especially in the later phases of the disturbance with a clear semi-diurnal signal (Thiel and Schriever, 1989), combined with the residence time of the resuspended particles in the water column for more than 10h (Thiel and Schriever, 1989; Greinert, 2015) indicate that these remaining $10 \%$ were most likely spread across the entire DEA and beyond. The sediment blanketing map should thus be considered as the minimum impact, with the SE sector being least impacted as already suggested by Thiel and Schriever (1989).

The sectors with the highest sediment blanketing are central southeast (CSE) and central west (CW) (Fig. 11a), where a high density of disturbance tracks also occurs (Fig. 11b). 
$\mathrm{X}$-ray studies aiming at measuring the deposition thickness were performed on selected MUC samples during SO077 (Fig. 11); results imply that sectors CS, central north $(\mathrm{CN})$, peripheral southeast (PSE) and central northeast (CNE) are most heavily influenced with thicknesses between 5 and $30 \mathrm{~mm}$ (Schriever and Thiel, 1992, Table H1). In the disturbance map, for example within sector PSE, only low disturbance is indicated, due to the very low density of tracks. A sample taken in sector CW (SO077_110MC_358, Fig. 11, Table H1) only shows a thin resedimented layer (1-2 mm), despite it being located in one of the most heavily disturbed areas (Fig. 11b) with high blanketing (Fig. 11a). This discrepancy could be explained by the more inaccurate positioning during SO77 (positions represent the ship position at the bottom contact time of the sampling gear) which hinders a punctual comparison on such a small scale. As implied in the disturbance map in the close vicinity of sampling station MC_358, there is a $\sim 100 \mathrm{~m} \times 70 \mathrm{~m}$ wide patch where only thin sediment blanketing has been calculated (Fig. 11a). In this respect differences between the ships' logged position and the devices' position on ground in 2015 varied sometimes by more than $100 \mathrm{~m}$ (Greinert, 2015). In 1992, this distance might have even been greater as the old RV Sonne did not have dynamic positioning systems. Considering the high blanketing thicknesses proximal to the tracks, a sample location offset of several tens of metres could considerably change the result. Samples during SO077 could have been taken within or next to a track or from one punctual location within a disturbed area, where not much sediment has been deposited (Fig. 11a). This again highlights the importance of being aware of the exact sampling positions and thus the need for detailed geo-referencing for the interpretation of the data.

However the generation of the disturbance intensity map is based on simplifications, not considering the specific sediment settling parameters as particle sizes, density of particles and water turbulence. It also did not include the local morphology, which has been proven to influence the sediment plume distribution (Peukert et al., 2018). Furthermore the microrelief of ripple crests and furrows within the track will also have an influence on the sediment blanketing thickness results from sediment cores, which again require detailed position knowledge for accurate sample interpretation. These factors could also be a reason for the deviating results from the SO77 X-ray studies compared to the disturbance map of this study. For more detailed investigations, this should be considered and implemented into calculations and further sampling methods to allow an appropriate comparison of the results.

\subsection{Sediment cover evolution through time}

The numerous optical data acquired by OFOS, AUV and ROV during all expeditions to the DEA facilitate a comparison of the impact and its evolution over the 26 years that passed between the first and the most recent visit to the DIS-
$\mathrm{COL}$ area. Due to the explained navigation uncertainties, especially during the early visits to the DEA (SO061, SO064), a direct comparison of exactly the same square metre of the sea floor is difficult, but the comparison of different locations within an about $150 \mathrm{~m}$ long section of one track seems more reasonable (Fig. 12). Generally, the fine morphology of the disturbance tracks appears to be smoothed out over time by currents and natural sedimentation, although the characteristic sequence of alternating crests and valleys is still clearly visible after 26 years (Boetius, 2015; Greinert, 2015).

Track V02 is one of the first tracks that have been created during PFEG 2 (Table 1) and could still be detected in different OFOS surveys in 1989 (SO61_OFOS10), 1990 (SO64_OFOS19) and 2015 (SO242_1_OFOS05; Fig. 12a). Figure $12 \mathrm{~b}$ shows the track only a few hours after it has been created. The characteristic plough structures are very prominent and the freshly broken-up sediment lumps appear brighter than the surrounding sediments. Half a year later, the track appears distinctly smoothed and covered by sediment (Fig. 12c) due to the resettled sediment from plough deployments PFEG 4 to 11 . Using the assumed sediment plume distribution of 100-120 m down-current and 20-30 m up-current of the location where OFOS 19 crossed track V02, the observations are within the proximal deposition areas of later PFEGs (Fig. 12a). The high sedimentation visible within this track is in accordance with the predictions of the disturbance map (Fig. 11a). Over the following 25 years until 2015 (Fig. 12d) the track structures continued to be smoothed out, but the differences between 1990 and 2015 are less distinct. This illustrates the immense impact of the evolving sediment plume and the proximal resettling of the sediment compared to the natural sedimentation and current induced shaping of the sea floor in the deep sea.

Track H15 was one of the last tracks, created during PFEG 11 (Table F1 in Appendix F). This track could be captured in OFOS dives from different deployments in the centre of the DEA; H15 was further covered by the AUV photomosaic of SO242 (Fig. 13a). Figure 13b of SO61 (OFOS17 from 1989) shows the freshly ploughed sediment within the disturbance track comparable to Fig. 12b. During SO106 in 1996 the track morphology is smoothed but broken-up sediment lumps are still visible (Fig. 13c). The sediment cover within this track appears less than for track V02. The smoothing continued until 2015 but the track ripple structures are still apparent. At one location captured in the photomosaic the H15 track crosses the V02 track (Fig. 13a), which allows a direct comparison of two tracks from different PFEGs. In 1992 V02 already appears much less distinct (Fig. 13e) than track H15 4 years later (Fig. 13c), again pointing at strong resedimentation initiated by the plough activities after PFEG2. In 2015 the track ripples appear even weaker for V02 (Fig. 13f). This illustrates that the still observable levels of the secondary disturbance through the sediment plume need to be interpreted with respect to their sequential age and respective PFEG deployments. It underlines the importance of careful 

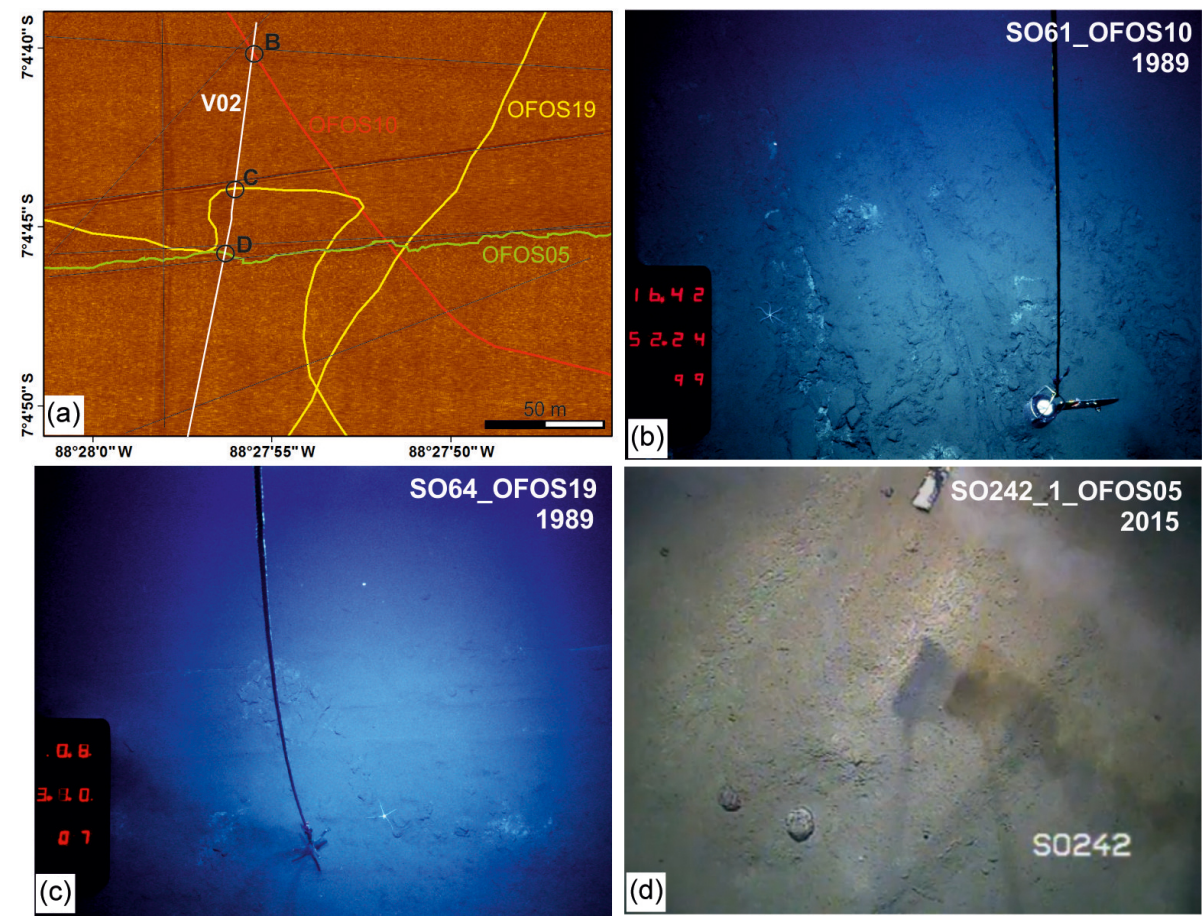

Figure 12. Evolution of track V02 over 26 years: (a) red: SO61_OFOS10, yellow: SO64_OFOS19, green: SO242_1_OFOS05; white line indicates track V02; black lines indicate surrounding plough marks (younger than V02). (b) Plough track a few hours after creation; (c) after 6 months distinct smoothing of the track structures; (d) after 26 years the track marks are still clearly visible but appear with distinct smoothed ripples. The identification of V02 in the different surveys was based on the orientation of the track being located close to another vertical running track west of V02 (indicated by the black line in a), which was also crossed by all OFOS surveys before. Due to the interval of the vertical tracks and being the first two vertical running tracks coming from the east, the identification of track V02 was successful and clear.

interpretations of the disturbance state of samples inside and near tracks. Furthermore, the track orientation with regard to the bottom current direction plays an essential role in terms of estimating the ecological impact coming along with the sediment plume; V02 runs parallel to the prevailing current direction, causing higher sedimentation within and very close to the track, whereas $\mathrm{H} 15$ runs perpendicular to the north- or south-directed bottom currents, which transported the sediment plume away from the track.

\section{Conclusions}

Results of our combination of legacy data from 1989 to 1996 with data from 2015 clearly indicate that underwater navigation and determining the accurate position of a sea floor sampling or observation location have been and still are difficult, even using state-of-the-art technology. The common approach used in this study that utilizes multiple hydro-acoustic data sets of different resolution that are referenced against an absolute GPS-based data set (ships bathymetry) improved the overall accuracy. This is a prerequisite for effective monitoring of deep-sea impacts from deep-sea mining or other spatial impact. Modern USBL and LBL systems linked with DVL and INS navigation on ROVs and AUVs can result in an absolute location accuracy of $<5 \mathrm{~m}$. High-resolution visual and acoustic data from AUV surveys emerged as a very resourceful tool for deep-sea surveys in general and monitoring impact experiments or even deep-sea mining long-term effects in particular.

The re-geo-referenced plough mark positions and the estimated sediment plume distribution allow a more precise evaluation of the primary and secondary disturbance. With respect to uncertainties in under water navigation of up to hundreds of metres, this knowledge is essential for a correct interpretation of physical and optical samples.

The geo-referencing of all available optical data from the different cruises to the DEA allowed a quasi-direct comparison of individual tracks over a time span of 26 years. This gave a unique insight into the temporal change of the intrack morphology through blanketing. Results underline the creation of a strong plume-induced sedimentation compared to the normal sedimentation. This will cause harm to the low-sedimentation regime adapted deep-sea ecosystem when industrial-scale deep-sea mining would occur. In this respect the results shown here are not unconditionally comparable to the impact of such a large-scale and long-lasting operation (Gollner et al., 2017). The absolute deposition will be much more as the top $10 \mathrm{~cm}$ (or more) of the sediment will 

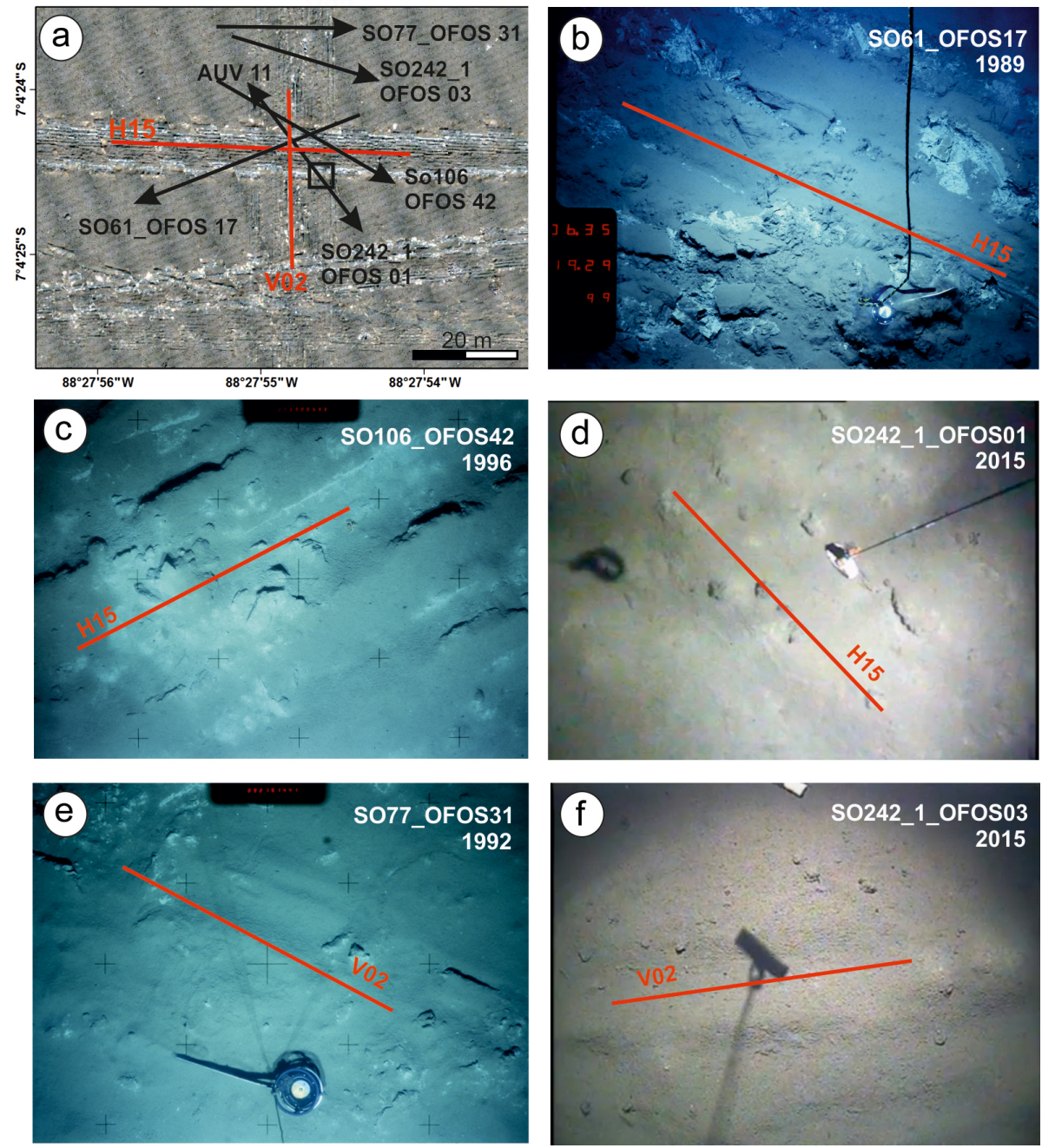

Figure 13. Evolution of tracks H15 and V02 over 26 years. (a) AUV-acquired photomosaic of a cross section in the central DEA, where OFOS data from the different DISCOL visits could be compared. Plough track H15 was one of the last tracks (PFEG 11) being created in 1989. (b) The plough mark is characterized by centimetre-sized freshly broken-up and shifted sediment piles, which appear distinctly smoothed in 1996 (c). About 26 years after its creation the track is still apparent, but the structures appear evenly covered by natural sedimentation (d). (e) Plough track V02 (PFEG 2) appears much more smoothed by higher resedimentation within the track in 1992 than H15. (f) After 26 years the characteristic ripple structures of the plough track appear only very weak.

be suspended, gravity flows will most likely be generated. The amount of finely grained material remaining in the water column might be more as well, and sediment blanketing most likely occurs up to tens of kilometres beyond the mined area (Boetius and Haeckel, 2018).

Detailed investigations are needed in coming impact experiments that should quantify the amount of sediment that is being resuspended to enable a conclusive interpretation of the quantitative results for sediment blanketing analyses (be it through visual, sedimentological or chemical means). Knowing bottom currents and the local bathymetry in high spatial and temporal resolution is a fundamental prerequisite for future impact experiments. Technologies exist and workflows are in place for conclusive assessments. 
Appendix A: Large-scale benthic impact experiments and associated sediment plume studies

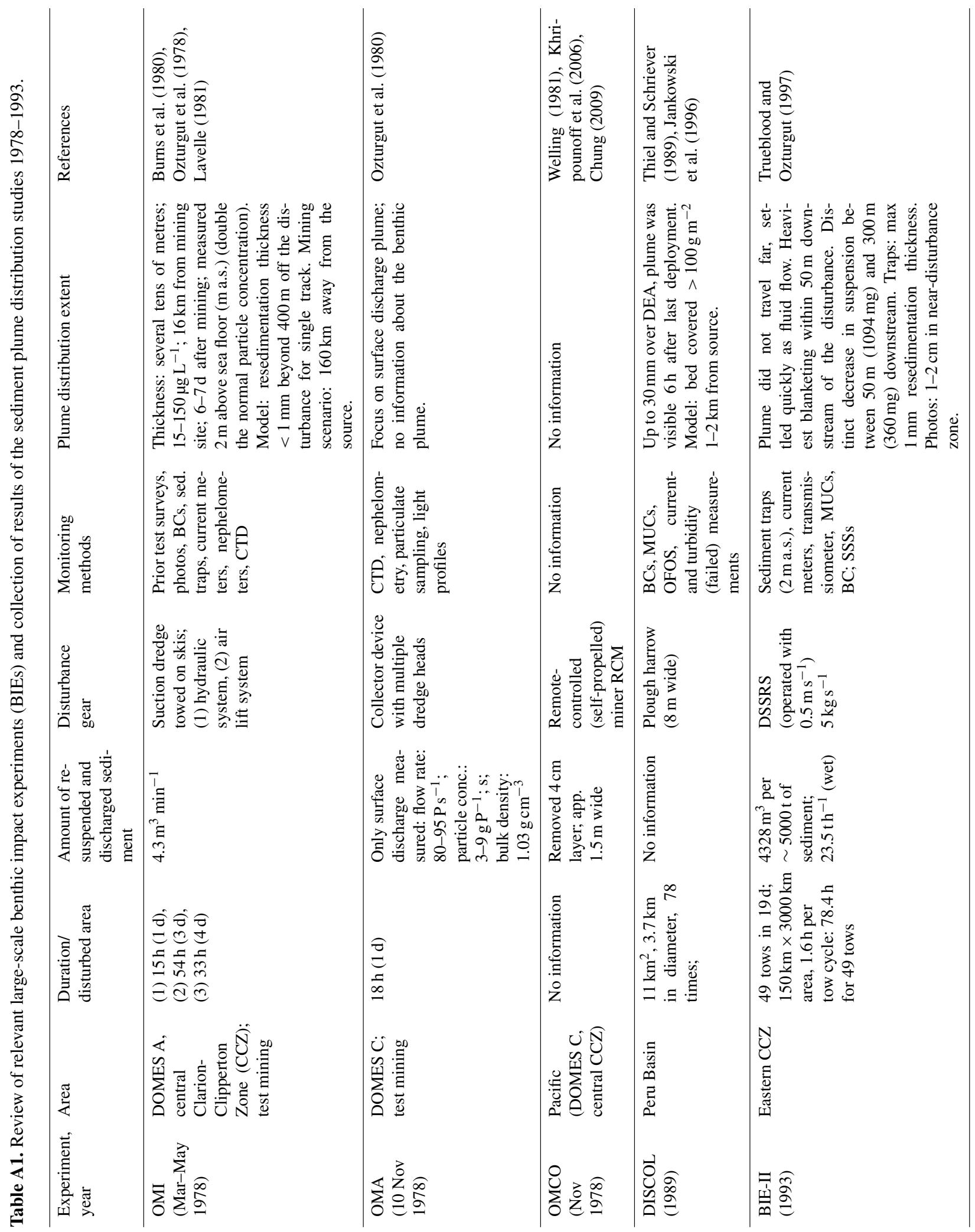




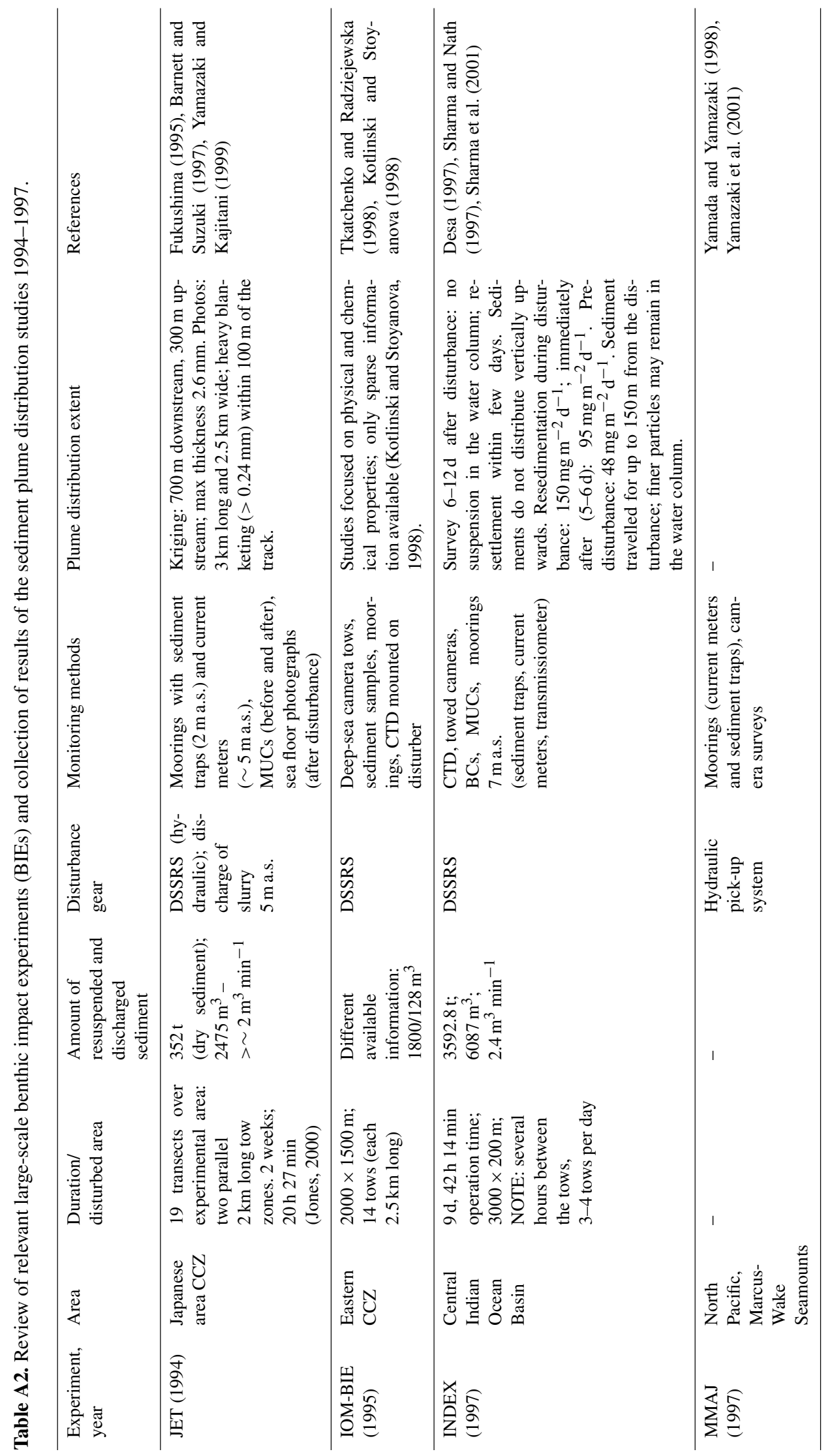


Appendix B: Hydro-acoustic and optical data sets acquired during cruise SO242_1

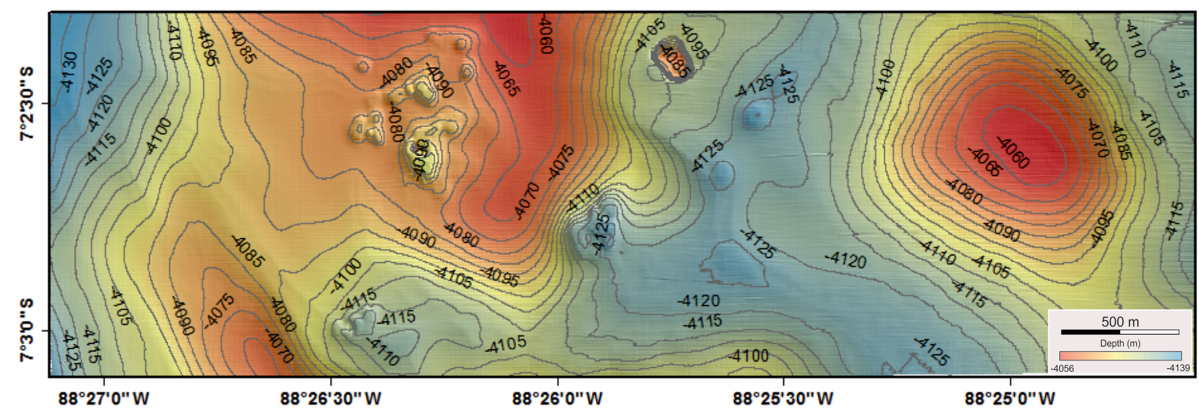

Figure B1. AUV bathymetric data set from Abyss195-SO242/1_075-1 north of the merged AUV MB data from the other AUV MB missions during cruise SO242_1 (see Sect. 2.2). This data set has been shifted $9 \mathrm{~m}$ down and $80 \mathrm{~m}$ towards the east according to the ship-based MB data and the merged AUV MB data set (see Sect. 2.3).

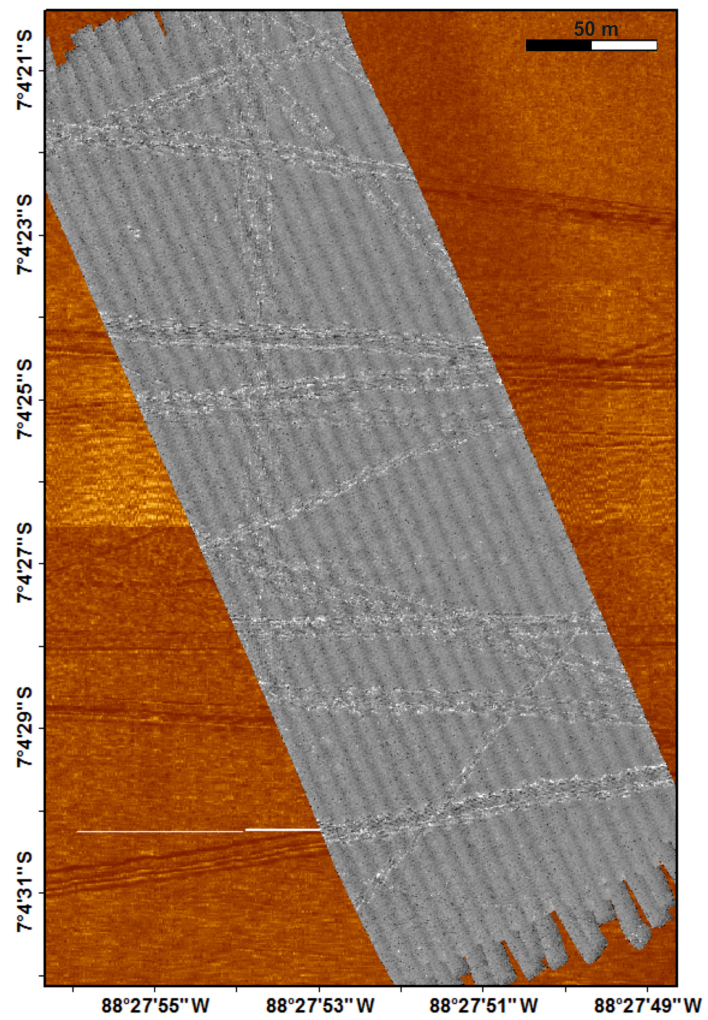

Figure B2. AUV-acquired photomosaic (Abyss199_SO242/1_102_1) within the central DEA (plotted on the SSS map) with a resolution of up to a few centimetres. 


\section{Terrain analysis of the working area/DEA}
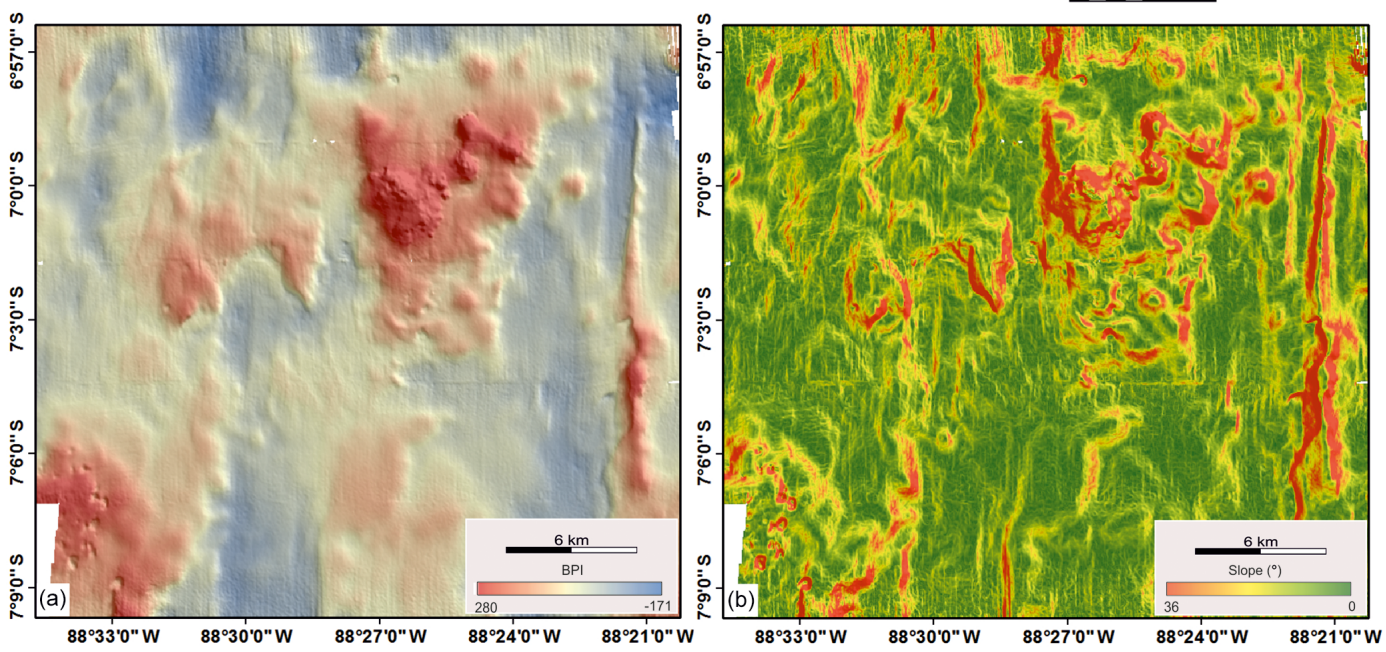

Figure B3. (a) Bathymetric position index (BPI) map of the ship-based bathymetric data indicating elevations (red coloured) and basins (blue coloured) within the area (scale factor 7600; grid cell size: $38 \mathrm{~m}$; inner radius: 100 cells; outer radius: 200 cells). (b) Slope map of the ship-based bathymetric data indicating the highest slopes in association with major morphological elevations. BPI and slope map have been calculated using the ArcGIS "Benthic Terrain Modeler (BTM)" add-in (Wright et al., 2012).
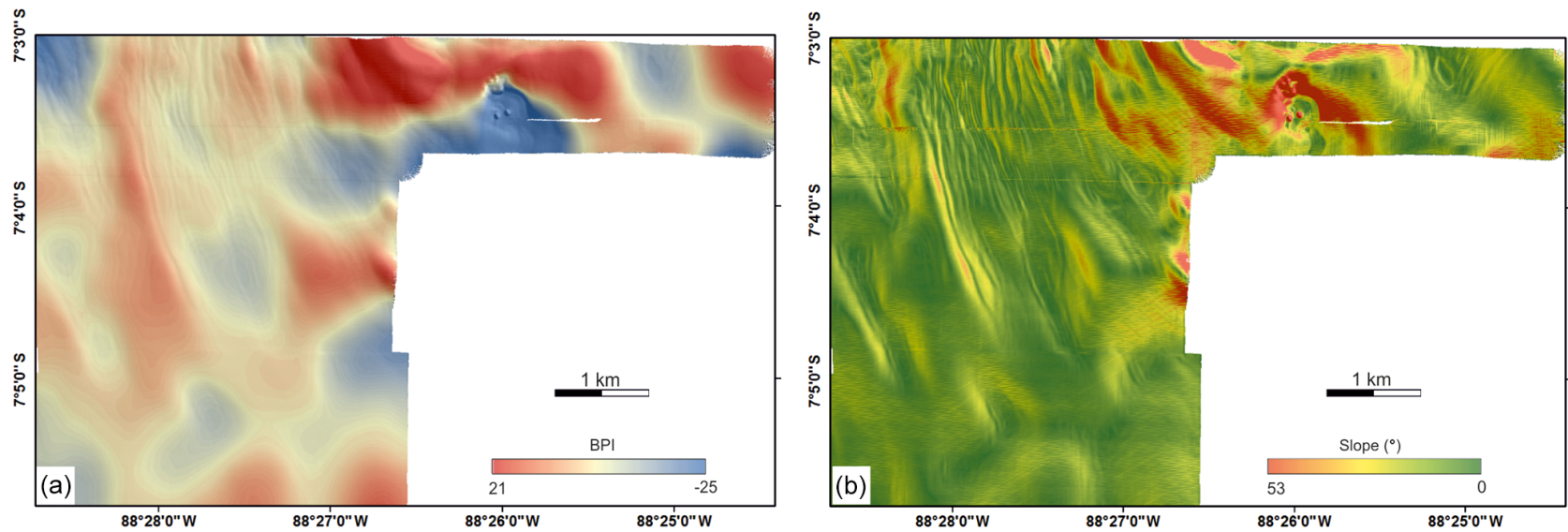

Figure B4. (a) BPI map of the AUV-acquired bathymetric data indicating elevations (red coloured) and basins (blue coloured) within the area (scale factor 1000; grid cell size: $2 \mathrm{~m}$; inner radius: 250 cells; outer radius: 500 cells). (b) Slope map of the AUV-acquired bathymetric data indicating low sloping terrain within the DEA and the highest slopes NE of the DEA in the hilly terrain. BPI and slope map have been calculated using the ArcGIS "Benthic Terrain Modeler (BTM)" add-in (Wright et al., 2012). 
Appendix C: Alignment of the different available acoustic and optical data sets

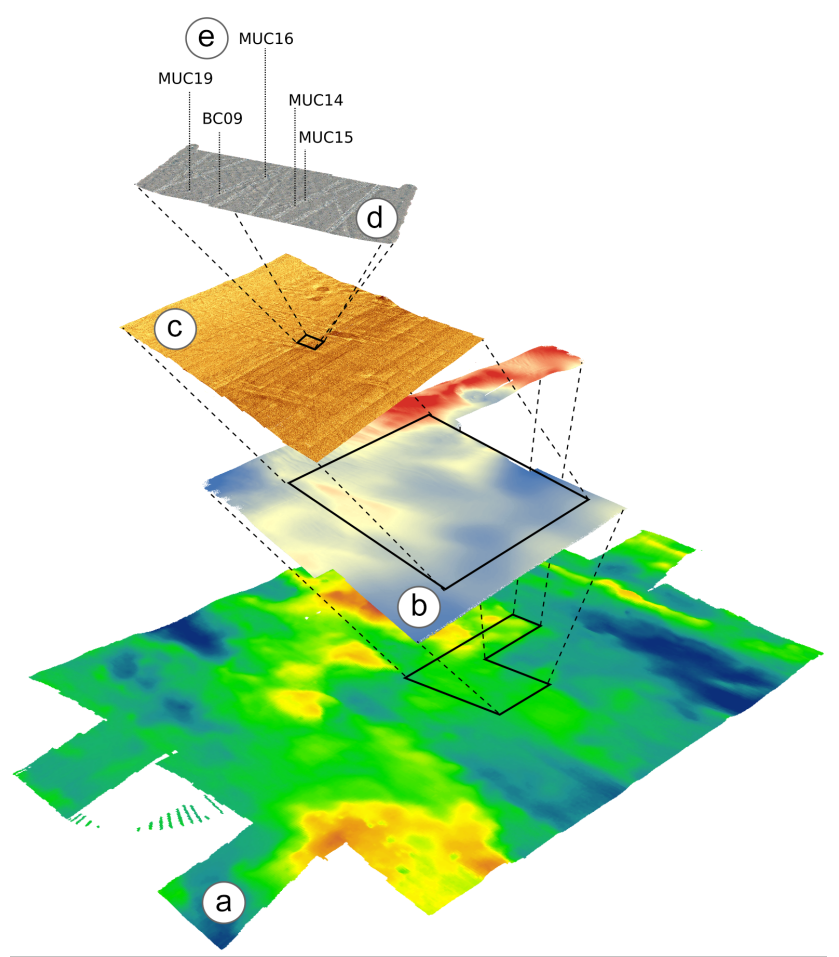

Figure C1. Schematic representation and overview of the alignment steps of the different data sets: the ship-acquired bathymetric map (a) was set as the base, where the AUV-acquired bathymetric data set (b) was aligned based on contour lines of prominent structures. The sidescan sonar map (c) and finally the photomosaics created from sea floor images (d) were then fitted based on representative structures (see text and Fig. 5 for details). The results were evaluated using the USBL positions of some sea floor sampling impacts visible in the images (e) as well as disturbance track sightings during ROV and OFOS dives during SO242-2 (not shown here).

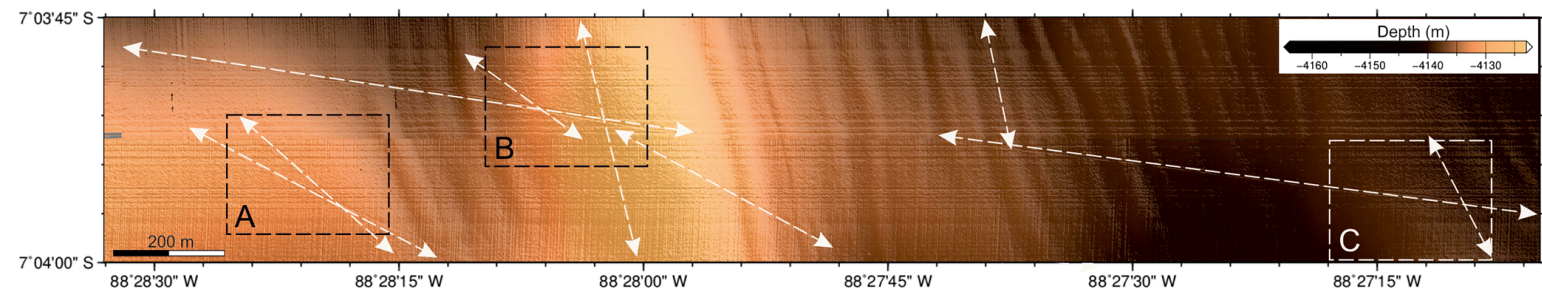

Figure C2. AUV-acquired bathymetric map ( $1 \mathrm{~m}$ resolution) showing the context setting of the three inlet maps from Fig. 5a, b and c. 


\section{Appendix D: USBL positioning of sampling gear - bottom contact}

The sampling locations at the bottom were determined during the cruise using USBL navigation (Greinert, 2015); the USBL transponder was mounted on the cable approximately $50 \mathrm{~m}$ above the sampling gear (BC, MUC and GC) and the position was recorded every $7 \mathrm{~s}$ over the course of the entire operation. To determine the sampling location, the USBL data were edited and erroneous signals were removed before the data were smoothed. The time of sampling and as a consequence the position were determined using the "wire tension" of the cable (Fig. D1).
USBL positioning has a minimum uncertainty of $0.2 \%$ of the slant range at ideal conditions (iXBlue, 2016). Water depths in the DEA range between 4065.86 and $4188.19 \mathrm{~m}$, resulting in a possible error between 8.1 and $8.4 \mathrm{~m}$ with regard to the sampling location. Through continuous measurements and editing the data afterwards, additional errors such as the transponder being mounted approximately $50 \mathrm{~m}$ a.s. (Greinert, 2015) were minimized.
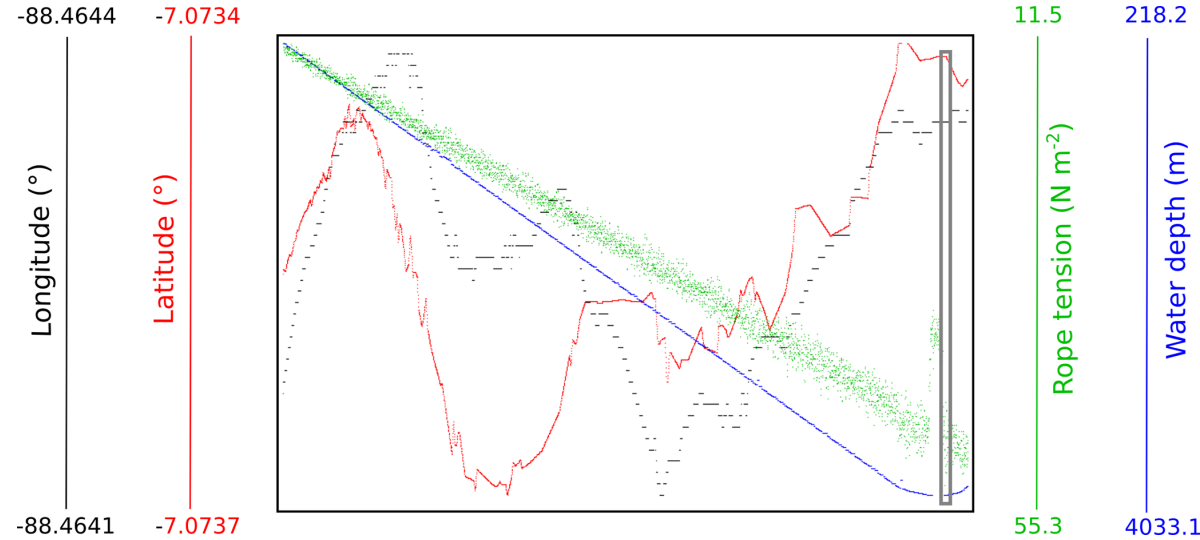

Figure D1. Determining the sea floor sampling position using data from USBL communication with position (longitude in black and latitude in red) and water depth (blue). In addition, the rope tension (green) was also considered to improve the accuracy of the result. Once the sampling gear hit the sea floor, the tension of the cable suddenly dropped as a few metres of cable are still paid out so that the sampling gear is not unintentionally towed over the sea floor. The sampling location is then identified as the position at the time when the "wire tension" increases again (black rectangle). 
Appendix E: Comparison of ship- and AUV-obtained data after alignment

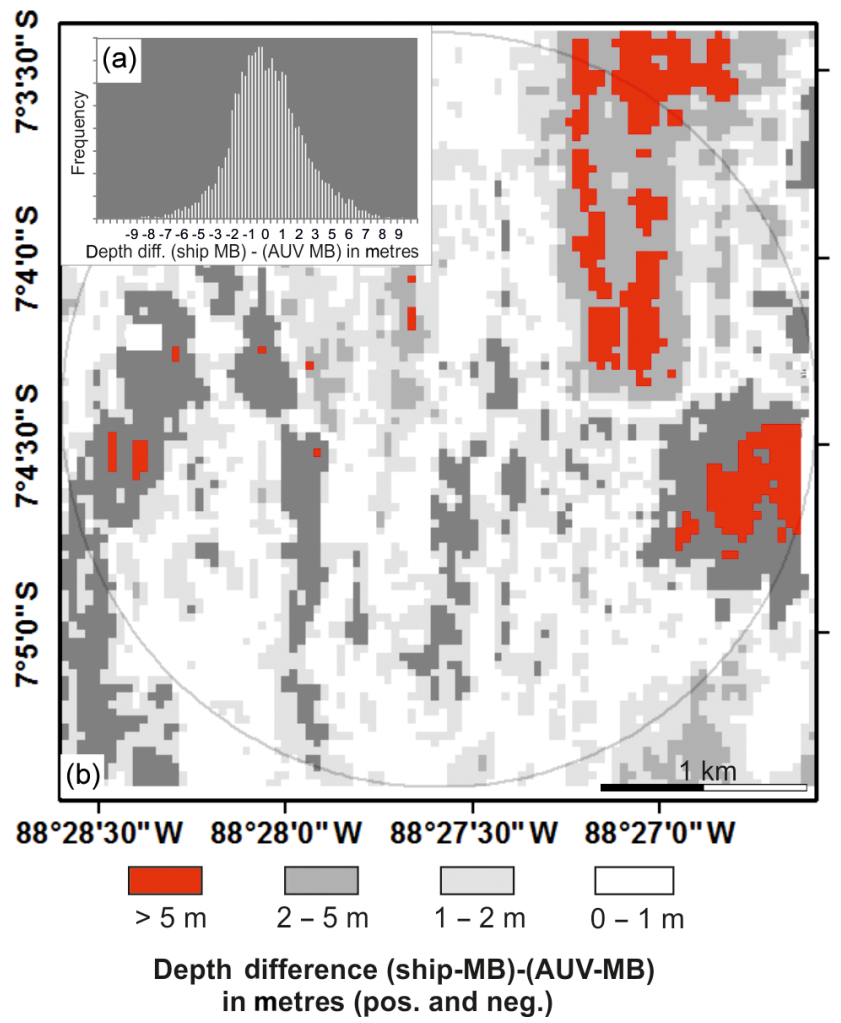

Figure E1. Grid (resolution $38 \mathrm{~m}$ ) showing the differences in depth measurements between the ship- and AUV-obtained bathymetric data after the alignment of both data sets within the DEA. The values show a mean of $0 \mathrm{~m}$ ranging with a median of $-0.5 \mathrm{~m}$ (a). Only in a few did areas the deviation between the bathymetric data sets exceed $5 \mathrm{~m} \mathrm{(b),} \mathrm{possibly} \mathrm{related} \mathrm{to} \mathrm{internal} \mathrm{inconsistency} \mathrm{between} \mathrm{the} \mathrm{different} \mathrm{AUV}$ MB surveys, which have been merged (see Sect. 2.2.1). 


\section{Appendix F: Age sequencing of plough tracks}

Table F1. Section from the logical $84 \times 84$ matrix where all crossings with their relative sequence (older: created earlier; younger: created later; matrix should be read column-wise) were included. The numbers indicate the source of information, which the sequencing is based on: 1: only SSS; 2: nodule coverage anomalies derived from AUV photos; 3: AUV or OFOS images; 4: sequence derived from cross-referencing. ?: no intersection. The entire matrix is not shown here due to its size but can be downloaded from the PANGAEA database (see "Data availability" https://doi.pangaea.de/10.1594/PANGAEA.905616, Gausepohl et al., 2019).

\begin{tabular}{|c|c|c|c|c|c|c|c|}
\hline Track_ID & V01 & V02 & V03 & V04 & V05 & V06 & V07 \\
\hline V01 & $\mathrm{xxx}$ & - & - & - & - & - & - \\
\hline V02 & - & $\mathrm{xxx}$ & - & - & - & - & - \\
\hline V03 & - & - & $\mathrm{xxx}$ & - & - & - & - \\
\hline V04 & - & - & - & $\mathrm{xxx}$ & - & - & - \\
\hline V05 & - & - & - & - & $\mathrm{xxx}$ & 4 older & - \\
\hline V06 & - & - & - & - & 4 younger & $\mathrm{xxx}$ & 4 older \\
\hline V07 & - & - & - & - & - & 4 younger & $\mathrm{xxx}$ \\
\hline V08 & - & - & - & - & - & 1 younger & 4 younger \\
\hline V09 & - & - & - & - & - & - & - \\
\hline V10 & - & - & - & - & - & 1 younger & - \\
\hline V11 & - & - & - & - & - & - & - \\
\hline H01 & 1 older & 1 older & - & 4 younger & 1 younger & 1 younger & 1 younger \\
\hline H02 & 4 younger & 4 older & - & 4 younger & 1 younger & 1 younger & 1 younger \\
\hline H03 & 1 younger & 4 older & - & 1 younger & 1 younger & 1 younger & 1 younger \\
\hline H04 & 1 older & 1 older & - & 1 older & 1 older & 1 older & 1 older \\
\hline H05 & 1 older & 1 older & - & 1 older & 1 older & 1 older & 1 older \\
\hline H06 & 1 younger & 1 older & - & 1 older & 1 younger & 1 younger & 1 younger \\
\hline H07 & - & - & - & - & 1 younger & 4 younger & 1 younger \\
\hline H08 & 1 older & 1 older & - & 1 older & 1 older & 1 older & 1 older \\
\hline H09 & 1 older & 1 older & - & 1 older & 4 older & 1 older & 1 older \\
\hline H10 & 1 older & 1 older & - & 1 older & 1 older & 1 older & 1 older \\
\hline H11 & 1 older & 3 older & - & 2 older & 1 older & 1 older & 1 older \\
\hline H12 & 1 older & 3 older & - & 2 older & 1 older & 1 older & 1 older \\
\hline H13 & 1 older & 1 older & - & 2 older & 1 older & 1 older & 1 older \\
\hline H14 & 1 older & 3 older & - & 2 older & 1 older & - & - \\
\hline H15 & 1 older & 3 older & - & 2 older & 1 older & 1 older & 1 older \\
\hline H16 & 1 older & 4 older & - & 2 younger & 4 younger & 4 younger & 4 younger \\
\hline H17 & 1 older & 3 older & - & 2 older & 1 older & 1 older & 1 older \\
\hline H18 & 1 older & 3 older & - & 2 older & 1 older & 1 older & 1 older \\
\hline H19 & 1 older & 3 older & - & 2 older & 1 older & 1 older & 1 older \\
\hline $\mathrm{H} 20$ & 1 older & 4 older & 4 older & 4 younger & 4 younger & 4 younger & 1 younger \\
\hline $\mathrm{H} 21$ & 1 younger & 4 older & 4 older & 1 younger & 1 younger & younger & 1 younger \\
\hline $\mathrm{H} 22$ & 1 younger & 1 older & 4 older & 1 younger & 1 younger & 4 younger & 1 younger \\
\hline $\mathrm{H} 23$ & 1 older & 1 older & 4 older & 1 older & 1 older & 1 older & 1 older \\
\hline
\end{tabular}


Appendix G: Offset between before and after the alignment of the different data sets

Table G1. Distance between the sea floor sampling positions visible in the geo-referenced photomosaic and post-processed USBL data positions.

\begin{tabular}{lr}
\hline Station SO242_1 & Distance (m) USBL - Mosaic \\
\hline BC06 & 6 \\
BC07 & 10 \\
BC08 & 12 \\
BC09 & 14 \\
BC10 & 13 \\
MUC14 & 17 \\
MUC15 & 20 \\
MUC16 & 15 \\
MUC19 & 25 \\
\hline
\end{tabular}

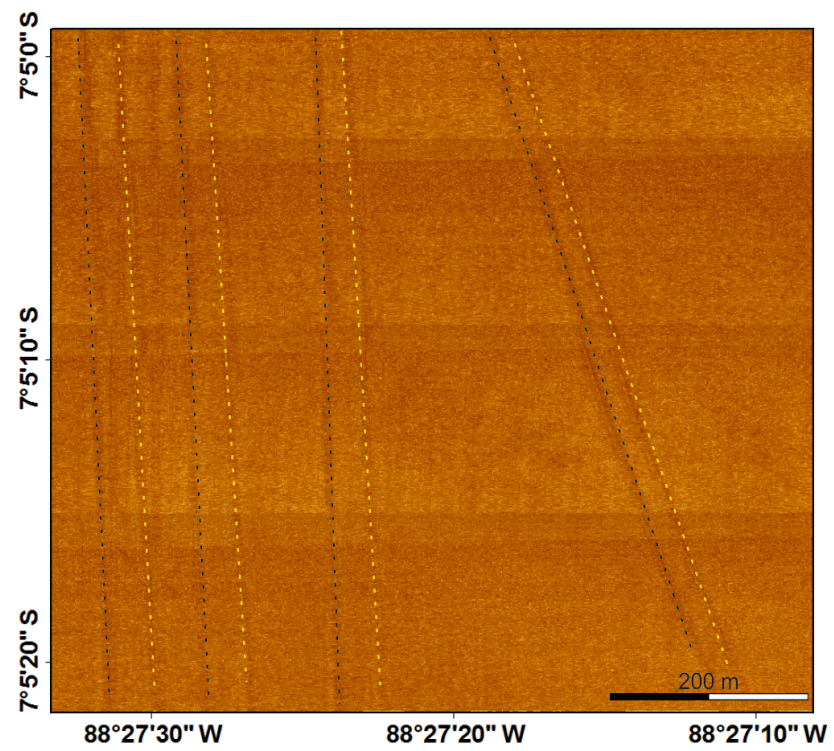

Figure G1. The plough marks visible in the SSS map show the offset of the SSS data before (yellow dotted) and after (black dotted) geo-referencing based on the MB data sets. An offset of approximately 30-50 m, in some areas also up to $80 \mathrm{~m}$, can be detected. 
Appendix H: Sampled sediment blanketing thicknesses from SO77 and SO242_1

Table H1. Thickness of resedimented particles determined by X-ray analysis of samples within the DEA during cruise SO77 in 1992 (after Schriever and Thiel, 1992).

\begin{tabular}{lrrlr}
\hline Ship_Station & DISCOL station & MUC & Sector & Resedimented layer (in millimetres) \\
\hline SO077_024 & 390 & 341 & CS & $10-30$ \\
SO077_033 & 399 & 344 & CNW & $1-2$ \\
SO077_055 & 418 & 347 & CNE & $7-10$ \\
SO077_056 & 419 & 348 & PSE & $5-20$ \\
SO077_075 & 439 & 351 & CN & $7-15$ \\
SO077_092 & 455 & 355 & PN & 3 \\
SO077_110 & 471 & 358 & CW & $1-2$ \\
\hline
\end{tabular}


Data availability. The final referenced hydro-acoustic maps and photomosaics (as GeoTIFF), as well as the disturbance tracks (as GIS-readable shape files), are available in the research data platform PANGAEA (https://doi.pangaea.de/10.1594/PANGAEA.905616, Gausepohl et al., 2019). Underwater photographs were georeferenced and uploaded to the annotation database BIIGLE 2.0 (Langenkämper et al., 2017). Data are available under https://annotate.geomar.de/projects/27, https://annotate. geomar.de/projects/28, https://annotate.geomar.de/projects/31, https://annotate.geomar.de/projects/32, https://annotate.geomar. $\mathrm{de} /$ projects/33 and https://annotate.geomar.de/projects/34 (access on request, last access: 12 March 2020) and can be accessed there. The raw photo data from the AUV camera surveys in the DEA can be found in Greinert et al. (2017, https://doi.org/10.1594/PANGAEA.882349).

Author contributions. FG has digitized the available analogue data from the initial DISCOL impact cruises, collected the entire set of study-relevant data from all DISCOL cruises from 1989 to 2015 and did the post-processing of navigation data from SO242 deployments. He substantially contributed to the methodology and the document writing. AH contributed to literature review and the methodology. She also created the figures and was substantially involved in the document writing. TS and KK contributed with the acquisition, processing, curation and data analysis of optical data. KK created the mosaics of the AUV-acquired photographs. JG was the supervisor and the initiator of this study, developed the study design and contributed to methodology strategies. He also substantially contributed to the document writing.

Competing interests. The authors declare that they have no conflict of interest.

Special issue statement. This article is part of the special issue "Assessing environmental impacts of deep-sea mining - revisiting decade-old benthic disturbances in Pacific nodule areas". It is not associated with a conference.

Acknowledgements. We thank the captain and crew of RV Sonne $\mathrm{SO} 242 / 1$ for their cooperation and valuable contribution to a successful cruise. The work was funded by the German Federal Ministry of Education and Research through the Mining Impact project (grant no. 03F0707A) of the Joint Programming Initiative of Healthy and Productive Seas and Oceans (JPIOceans). Financial support was also provided by the EU project MIDAS (FP7, grant agreement no. 603418). We express our gratitude to the GEOMAR AUV team for their splendid support and professional attitude during the cruise. Gerd Schriever and the other anonymous referee are thanked for their valuable comments and contributions to the manuscript. This is publication no. 34 of the DeepSea Monitoring Group at GEOMAR.
Financial support. The article processing charges for this openaccess publication were covered by a Research Centre of the Helmholtz Association.

Review statement. This paper was edited by Jack Middelburg and reviewed by Gerd Schriever and one anonymous referee.

\section{References}

Barnett, B. G. and Suzuki, T.: The Use of Kriging to Estimate Resedimentation in the JET Experiment, in: Proceedings of International Symposium on Environmental Studies for Deep sea Mining, Tokyo, Japan, 143-151, 1997.

Becker, H. J., Grupe, B., Oebius, H., and Liu, F.: The behaviour of deep-sea sediments under the impact of nodule mining processes, Deep-Sea Res. Pt. II, 48, 3609-3627, 2001.

Bluhm, H.: Monitoring megabenthic communities in abyssal manganese nodule sites of the east pacific ocean in association with commercial deep sea mining, Aquat. Conserv., 4, 187-201, 1994.

Bluhm, H. and Thiel, H.: Photographic and video surveys for large scale animal and seafloor surface charting aiming at ecological characterization of habitats and communities, Proceedings of the International Seminar on Deep Sea-bed Mining Technology, COMRA, 18-20 October 1996, Beijing, PR China, C15-C23, 1996.

Boetius, A.: RV Sonne Fahrtbericht/cruise report SO242-2 [SO242/2]: JPI Oceans Ecological Aspects of Dep-Sea Mining, DISCOL revisited, Guayaquil-Guayaquil (Ecuador), 28 August1 October 2015, GEOMAR Report, N. Ser. 027, GEOMAR Helmholtz-Zentrum für Ozeanforschung, Kiel, Germany, 552 pp., https://doi.org/10.3289/GEOMAR_REP_NS_27_2015, 2015.

Boetius, A. and Haeckel, M.: Mind the seafloor, Science, 359, 34 36, https://doi.org/10.1126/science.aap7301, 2018.

Burns, R.: Observations and measurements during the monitoring of deep ocean manganese nodule mining tests in the North pacific, March-May 1978, Vol. 47, US Department of Commerce, National Oceanic and Atmospheric Administration, Environmental Research laboratories, Colorado, USA, 1980.

Brockett, T. and Richards, C. Z.: Deepsea Mining Simulator For Environmental Impact Studies, Sea Technol., 35, 77-82, 1994.

Chung, J.: Deep-Ocean Mining Technology III: Developments. International Society of Offshore and Polar Engineers, Proceedings of The Eighth (2009) ISOPE Ocean Mining Symposium, 20-24 September 2009, Chennai, India, 2009.

Desa, F.: Initial Results of India's Environmental Impact Assessment of Nodule Mining, in: Proceedings of International Symposium on Environmental Studies for Deep sea Mining, 1997.

Devey, C. W., Greinert, J., Boetius, A., Augustin, N., Melchior, C., and Yeo, I.: How volcanically active are the abyssal plains? Evidence for recent volcanism and fluid 7 circulation on $20 \mathrm{Ma}$ Nazca Plate seafloor, J. Volcanol. Geotherm. Res., submitted, 2020.

Drazen, J. C., Leitner, A. B., Morningstar, S., Marcon, Y., Greinert, J., and Purser, A.: Observations of deep-sea fishes and mobile scavengers from the abyssal DISCOL experimental mining area, 
Biogeosciences, 16, 3133-3146, https://doi.org/10.5194/bg-163133-2019, 2019.

Flood, R. D.: Classification of sedimentary furrows and a model for furrow initiation and evolution, GSA Bulletin, 94, 630-639, https://doi.org/10.1130/00167606(1983)94<630:COSFAA>2.0.CO;2, 1983.

Foell, E. J., Thiel, H., and Schriever, G.: DISCOL: A longterm, large-scale, disturbance-recolonization experiment in the Abyssal Eastern Tropical South Pacific Ocean, 22nd Annual OTC, 7-10 May 1990, Houston, Texas, OTC 6328, 497-503, 1990.

Fukushima, T.: Overview Japan Deep-sea impact experiment JET, Proceedings of the First ISOPE Ocean mining Symposium, Tsukuba, Japan, ISOPE, 47-53, 1995.

Gausepohl, F., Hennke, A., Schoening, T., Köser, K., and Greinert, J.: Geo-referenced acoustic and optical data sets from the DISCOL area in the Peru-basin acquired during RV SONNE cruise SO242/1, PANGAEA, https://doi.org/10.1594/PANGAEA.905616, 2019.

GEOMAR Helmholtz-Zentrum für Ozeanforschung: Remotely Operated Vehicle "ROV KIEL 6000", Journal of large-scale research facilities, 3, A117, https://doi.org/10.17815/jlsrf-3-160, 2017.

Gillard, B., Purkiani, K., Chatzievangelou, D., Vink, A., Iversen, M. H., and Thomsen, L.: Physical and hydrodynamic properties of deep sea mining-generated, abyssal sediment plumes in the Clarion Clipperton Fracture Zone (eastern-central Pacific), Elem. Sci. Anth., 7, p. 5, https://doi.org/10.1525/elementa.343, 2019.

Gollner, S., Kaiser, S., Menzel, L., Jones, D. O. B., Brown, A., Mestre, N. C., van Oevelen, D., Menot, L., Colaco, A., Canals, M., Cuvelier, D., Durden, J. M., Gebruk, A., Egho, G. A., Haeckel, M., Marcon, Y., Mevenkamp, L., Morato, T., Pham, C. K., Purser, A., Sanchez-Vidal, A., Vanreusel, A., Vink, A., and Martinez Arbizu, P.: Resilience of benthic deep-sea fauna to mining activities, Mar. Environ. Res., 129, 76-101, https://doi.org/10.1016/j.marenvres.2017.04.010, 2017.

Greinert, J.: RV Sonne Fahrtbericht/cruise report SO242-1 [SO242/1], JPI Oceans Ecological Aspects of Deep-Sea Mining, DISCOL revisited, Guayaquil-Guayaquil, 28 July25 August 2015, GEOMAR Report, N. Ser. 026, GEOMAR Helmholtz-Zentrum für Ozeanforschung, Kiel, Germany, 290 pp., https://doi.org/10.3289/GEOMAR_REP_NS_26_2015, 2015.

Greinert, J., Schoening, T., Köser, K., and Rothenbeck, M.: Seafloor images and raw context data along AUV tracks during SONNE cruises SO239 and SO242/1. GEOMAR Helmholtz Centre for Ocean Research Kiel, PANGAEA, https://doi.org/10.1594/PANGAEA.882349, 2017.

Grupe, B., Becker, H. J., and Oebius, H.: Geotechnical and sedimentological investigations of deep-sea sediments from a manganese nodule field of the Peru Basin, Deep-Sea Res. Pt. II, 48, 3593-3608, 2001.

iXBlue: Datasheet Posidonia II, iXBlue, available at: https: //www.ixblue.com/products/posidonia\#downloads (last access: 11 March 2020), 2016.

Jankowski, J. A. and Zielke, W.: The mesoscale sediment transport due to technical activities in the deep sea, Deep-Sea Res. Pt. II, 48, 3487-3521, 2001.
Jankowski, J. A., Malcherek, A., and Zielke, W.: Numerical modeling of suspended sediment due to deep sea mining, J. Geophys. Res., 101, 3545, https://doi.org/10.1029/95JC03564, 1996.

Jones, A. T.: Review of Benthic Impact Experiments Related to Seabed Mining, Offshore Technology Conference, Houston (Texas), USA, 1-3, 2000.

Jones, D. O. B., Kaiser, S., Sweetman, A. K., Smith, C. P., Menot, L., Vink, A., Trueblood, D., Greinert, J., Billett, D. S. M., Martinez Arbizu, P., Radziejewska, T., Singh, R., Ingole, B., Stramann, T., Simon-Lledó, E., Durden, J. M., and Clark, M. R.: Biological responses to disturbance from simulated deepsea polymetallic nodule mining, PLoS ONE, 12, e0171750, https://doi.org/10.1371/journal.pone.0171750, 2017.

Khripounoff, A., Caprais, J.-C., Crassous, P., and Etoubleau, J.: Geochemical and biological recovery of the disturbed seafloor in polymetallic nodule fields of the Clipperton-Clarion Fracture Zone (CCFZ) at 5,000-m depth, Limnol. Oceanogr., 51, 2033 2041, https://doi.org/10.4319/lo.2006.51.5.2033, 2006.

Klein, H.: Near-bottom currents in the Peru Basin, DISCOL experimental area, Deutsche Hydrographische Zeitschrift, 45, 31-42, 1993.

Klein, H.: Near-bottom currents and bottom boundary layer variability over manganese nodule fields in the peru basin, se-pacific, Deutsche Hydrographische Zeitschrift, 48, 147, https://doi.org/10.1007/BF02799384, 1996.

Kongsberg, S.: EM 120 Multibeam Echo Sounder, Product Description, Kongsberg Maritime AS, Norway, Bremerhaven, Pangaea, 44 pp., available at: http://epic.awi.de/26725/1/Kon2007a. pdf (last access: 18 March 2020), 2007.

Kotlinski, R. and Stoyanova, V.: Physical, Chemical, And Geological Changes of Marine Environment Caused By the Benthic Impact Experiment At the 10M BIE Site, in: The Eighth International Offshore and Polar Engineering Conference, International Society of Offshore and Polar Engineers, May 1998, Montreal, Canada, 1998.

Kotlinski, R. and Stoyanova, V.: Physical, Chemical, and Geological Changes of Marine Environment Caused by the Benthic Impact Experiment at the 10M BIE Site, in: Proceedings of the Eighth (1998) International Offshore and Polar Engineering Conference, 24-29 May 1999, Montreal, Canada, Vol. 1, 277-281, International Society of Offshore and Polar Engineers, 1999.

Kuhn, T., Rühlemann, C., Wiedicke-Hombach, M., Rutkowsky, J., Wirth, H., Koenig, D., Kleinen, T., and Mathy, T.: Tiefseeförderung von Manganknollen, Schiff \& Hafen, 5, 78-83, 2011.

Kwasnitschka, T., Köser, K., Sticklus, J., Rothenbeck, M., Weiß, T., Wenzlaff, E., Schoening, T., Triebe, L., Steinführer, A., Devey, C., and Greinert, J.: DeepSurveyCam a deep ocean optical mapping system, Sensors, 16, 164, https://doi.org/10.3390/s16020164, 2016.

Langenkämper, D., Zurowietz, M., Schoening, T., and Nattkemper, T. W.: BIIGLE 2.0 - Browsing and Annotating Large Marine Image Collections, Front. Mar. Sci., 4, 83, https://doi.org/10.3389/fmars.2017.00083, 2017.

Lavelle, J., Ozturgut, E., Baker, E., and Swift, S.: Dispersal and resedimentation of the benthic plume from deep-sea mining operations: a model with calibration, Mar. Mining, 3, 59-93, 1981. 
Linke, P. and Lackschewitz, K.: autonomous Underwater Vehicle ABYSS, Journal of Large-Scale Research Facilities, 2, A79, https://doi.org/10.17815/jlsrf-2-149, 2016.

Lurton, X.: Forty years of progress in multibeam echosounder technology for ocean investigation, Journal of Acoustical Society of America, 141, 3948, https://doi.org/10.1121/1.4988962, 2017.

Mahatma, R.: Meiofauna communities of the Pacific Nodule Province: abundance, diversity, and community structure, $\mathrm{PhD}$ thesis, University of Oldenburg, Germany, 2009.

Martinez-Arbizu, P. and Haeckel, M.: RV Sonne Fahrtbericht/cruise report SO239: Eco Response assessing the ecology, connectivity, and resilience of ploymetallic nodule field systems, Balboa (Panama)-Monzanillo (Mexico), 11 March30 April 2015, GEOMAR Report, N. Ser. 025, GEOMAR Helmholtz-Zentrum für Ozeanforschung, Kiel, Germany, 204 pp., https://doi.org/10.3289/GEOMAR_REP_NS_25_2015, 2015.

McCave, I.: Size-spectra and aggregation of suspended particles in the deep ocean, Deep Sea Res., 31, 329-352, 1984.

Melchior, C.: Geological interpretation of bathymetric and backscatter data, Hydrographische Nachrichten, HN107, Deutsche Hydrographische Gesellschaft, 15-19, 2017.

Miljutin, D. M., Miljutina, M. A., Arbizu, P. M., and Galéron, J.: Deep sea nematode assemblage has not recovered 26 years after experimental mining of polymetallic nodules (Clarion-Clipperton Fracture Zone, Tropical Eastern Pacific), Deep-Sea Res. Pt. I, 58, 885-897, https://doi.org/10.1016/j.dsr.2011.06.003, 2011.

Oebius, H. U., Becker, H. J., Rolinski, S., and Jankowski, J. A.: Parametrization and evaluation of marine environmental impacts produced by deep-sea manganese nodule mining, Deep-Sea Res. Pt. II, 48, 3453-3467, 2001.

Ozturgut, E., Anderson, G. C., Burns, R. E., Lavelle, J. W., and Swift, S. A.: Deep ocean mining of manganese nodules in the North Pacific: Pre-mining environmental conditions and anticipated mining effects, NOAA Technical Memorandum ERL, MESA-33, Boulder, CO, 133 pp., 1978.

Ozturgut, E., Lavelle, J., Steffin, O., and Swift, S.: Environmental investigations during manganese nodule mining tests in the north equatorial Pacific in November 1978, NOAA Technical Memorandum ERL, MESA-48, Boulder, CO, 1980.

Peukert, A., Schoening, T., Alevizos, E., Köser, K., Kwasnitschka, T., and Greinert, J.: Understanding Mn-nodule distribution and evaluation of related deep-sea mining impacts using AUV-based hydroacoustic and optical data, Biogeosciences, 15, 2525-2549, https://doi.org/10.5194/bg-15-2525-2018, 2018.

Purser, A., Marcon, Y., and Boetius, A.: Return to DISCOL. 26 years after simulated nodule mining, available at: https://Epic. awi.de (last access: 12 March 2020), hdl:10013/epic.46846.d001, 2016.

Radziejewska, T.: Responses of deep sea meiobenthic communities to sediment disturbance simulating effects of polymetallic nodule mining, Int. Rev. Hydrobiol., 87, 457-477, https://doi.org/10.1002/1522-2632(200207)87:4<457::AIDIROH457>3.0.CO;2-3, 2002.

Robinson, A. R. and Kupferman, S. L.: Dispersal from deep ocean sources: physical and related scietific processes, 104 pp., Albuquerque, Sandia National Laboratories, 1985.
Schoening, T.: Source code for the Compact mophologybased Nodule Detection (CoMoNod) algorithm, PANGAEA, https://doi.org/10.1594/PANGAEA.875070, 2017.

Schoening, T., Jones, O. D., and Greinert, J.: Compact morphologybased polymetallic nodule delineation, Sci. Rep.-Basel, 7, 13338, https://doi.org/10.1038/s41598-017-13335-x, 2017.

Schriever, G.: Cruise Report DISCOL 2, Sonne - Cruise 64, Berichte aus dem Zentrum für Meeres- und Klimaforschung der Universität Hamburg, Nr. 6, Institut für Hydrobiologie und Fischreiwissenschft, Hamburg, 1990.

Schriever, G. and Thiel, H.: Cruise Report DISCOL 3, Sonne Cruise 77, Report No. 2, Reihe E: Hydrobilogie und Fischereiwissenschaft, Zentrum für Meeres- und Klimaforschung, Hamburg, 1992.

Schriever, G., Koschinsky, A., and Bluhm, H.: Cruise Report ATESEPP (Impact of potential technical interventions on the deepsea ecosystem of the southeast Pacific off Peru), Report No. 11, Reihe E: Hydrobiologie und Fischereiwissenschaft, Zentrum für Meeres- und Klimaforschung, Hamburg, 195 pp., 1996.

Sharma, R.: Assessment of Impact on Seafloor Features in INDEX Area, Mar. Georesour. Geotec., 18, 237-250, 2000.

Sharma, R.: Indian Deep sea Environment Experiment (INDEX): An appraisal, Deep-Sea Res. Pt. II, 48, 3295-3307, https://doi.org/10.1016/S0967-0645(01)00041-8, 2001.

Sharma, R. and Nath, B. N.: Benthic disturbance and monitoring experiment in the Central Indian Ocean Basin, in: Proceedings of the Second (1997) ISOPE Ocean Mining Symposium, edited by: Chung, J. S. and Hong, S., 2. ISOPE Ocean Mining Symp., 24-26 November 1997, Soeul, Korea, 1997.

Sharma, R., Nagender Nath, B., Parthiban, G., and Jai Sankar, S.: Sediment redistribution during simulated benthic disturbance and its implications on deep seabed mining, Deep-Sea Res. Pt. II, 48, 3363-3380, https://doi.org/10.1016/S0967-0645(01)000467, 2001.

Simon-Lledó, E., Bett, B. J., Huvenne, V., Köser, K., Schoening, T., Greinert, J., and Jones, D.: Biological effects 26 years after simulated deep-sea mining, Sci. Rep.-UK, 9, 8040, https://doi.org/10.1038/s41598-019-44492-w, 2019.

Thiel, H. and Schriever, G.: Cruise Report DISCOL1, Sonne Cruise 61, Berichte aus dem Zentrum für Meeres- und Klimaforschung der Universität Hamburg, Nr. 3, Institut für Hydrobiologie und Fischereiwissenschaft, Hamburg, 1989.

Thiel, H., Schriever, G., Bussau, C., and Borowski, C.: Manganese nodule crevice fauna, Deep-Sea Res. Pt. I, 40, 419-423, 1993.

Tkatchenko, G. G. and Radziejewska, T.: Recovery and recolonization processes in the area disturbed by a polymetallic nodule collector simulator, in: Proc. 8th ISOPE Conf., edited by: Chung, J. S., Frederking, R. M. W., Saeki, H., Moshagen, H., Vol. II, Montreal, Canada, International Society of Offshore and Polar Engineers, 282-286, 1998.

Trueblood, D. D. and Ozturgut, E.: The Benthic Impact Experiment?: A Study of the Ecological Impacts of Deep Seabed Mining on Abyssal Benthic Communities, in: Proceedings of the Seventh (1997) International Offshore and Polar Engineering Conference, 25-30 May 1997, Honolulu, Hawaii, USA, Vol. I, International Society of Offshore and Polar Engineers, 1997.

Tsurusaki, K.: Concept and Basic Design of the Plume Discharge, in: Proceedings of International Symposium on Environmental 
Studies for Deep sea Mining (1997), Metal Mining Agency of Japan (MMAJ), 127-132, 1997.

Vanreusel, A., Hilario, A., Ribeiro, P. A., Menot, L., and Martinez Arbizu, P.: Threatened by mining, polymetallic nodules are required to preserve abyssal epifauna, Sci. Rep.-UK, 6, 26808, https://doi.org/10.1038/srep26808, 2016.

Welling, C. G.: An Advanced Design Deep Sea Mining System, Offshore Technology Conference, 4-7 May, Houston, Texas, OTC 4094-MS, https://doi.org/10.4043/4094-MS, 1981.

Wessel, P. and Smith, W. H. F.: A global, self-consistent, hierarchical, high-resolution shoreline database, J. Geophys. Res., 101, 8741-8743, https://doi.org/10.1029/96JB00104, 1996.

Wessel, P., Smith, W. H. F., Scharroo, R., Luis, J., and Wobbe, F.: Generic Mapping Tools: Improved Version Released, EOS T. Am. Geophys. Un., 94, 409-410, https://doi.org/10.1002/2013EO450001, 2013.

Wright, D., Pendleton, M., Boulware, J., Walbridge, S., Gerlt, B., Eslinger, D., Sampson, D., and Huntley, E.: ArcGIS Benthic TerrainModeler (BTM), v. 3.0, Environmental Systems ResearchInstitute, NOAA Coastal Services Center, Massachusetts Officeof Coastal Zone Management, available at: http://esriurl.com/5754 (last access: 17 April 2018), 2012.
Yamada, H. and Yamazaki, T.: Japan's ocean test of the nodule mining system, in: The Eigth International Offshore and Polar Engineering Conference, International Society of Offshore and Polar Engineers, May 1998, Montreal, Canada, International Society of Offshore and Polar Engineers, 1998.

Yamazaki, T. and Kajitani, Y.: Deep-Sea environment and impact experiment to it, in: The Ninth International Offshore and Polar Engineering Conference, International Society of Offshore and Polar Engineers, June 1999, Brest, France, International Society of Offshore and Polar Engineers, 1999.

Yamazaki, T., Kuboki, E., and Yoshida, H.: Tracing Collector Passes and Preliminary Analysis of Collector Operation, in: Proceedings of the Third (1999) Ocean Mining Symposium, 8-10 November 1999, Goa, India, International Society of Offshore and Polar Engineers, 55-62, 1999.

Yamazaki, T., Kuboki, E., and Uehara, D.: Resedimentation Analysis from Seafloor Photographs, in: Proceedings of the Eleventh (2001) International Offshore and Polar Engineering Conference, 17-22 June, Stavanger, Norway, Vol. I, International Society of Offshore and Polar Engineers, 528-535, 2001. 